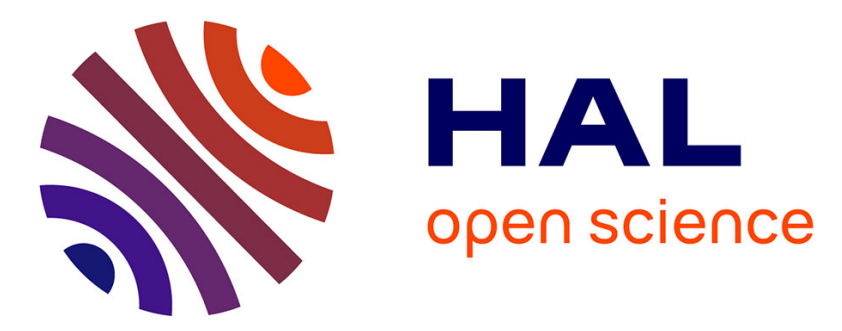

\title{
Aromatase in the brain of teleost fish: expression, regulation and putative functions.
}

Nicolas Diotel, Yann Le Page, Karen Mouriec, Sok-Keng Tong, Elisabeth

Pellegrini, Colette Vaillant, Isabelle Anglade, François Brion, Farzad Pakdel, Bon-Chu Chung, et al.

\section{To cite this version:}

Nicolas Diotel, Yann Le Page, Karen Mouriec, Sok-Keng Tong, Elisabeth Pellegrini, et al.. Aromatase in the brain of teleost fish: expression, regulation and putative functions.. Frontiers in Neuroendocrinology, 2010, 31 (2), pp.172-92. 10.1016/j.yfrne.2010.01.003 . hal-00472008

\section{HAL Id: hal-00472008 https://hal.science/hal-00472008}

Submitted on 9 Apr 2010

HAL is a multi-disciplinary open access archive for the deposit and dissemination of scientific research documents, whether they are published or not. The documents may come from teaching and research institutions in France or abroad, or from public or private research centers.
L'archive ouverte pluridisciplinaire HAL, est destinée au dépôt et à la diffusion de documents scientifiques de niveau recherche, publiés ou non, émanant des établissements d'enseignement et de recherche français ou étrangers, des laboratoires publics ou privés. 
Aromatase in the brain of teleost fish: expression, regulation and putative functions

Nicolas Diotel $^{1}$, Yann Le Page ${ }^{1}$, Karen Mouriec ${ }^{1 *}$, Sok-Keng Tong ${ }^{2}$, Elisabeth Pellegrini ${ }^{1}$,

Colette Vaillant ${ }^{1}$, Isabelle Anglade ${ }^{1}$, François Brion ${ }^{3}$, Farzad Pakdel $^{4}$, Bon-chu Chung ${ }^{2}$, Olivier $\mathrm{Kah}^{1}$

${ }^{1}$ Neurogenesis And Estrogens, UMR CNRS 6026, IFR 140,

Université de Rennes 1,

Rennes, France

${ }^{2}$ Institute of Molecular Biology

Academia Sinica

Taipei, Republic of China

${ }^{3}$ INERIS

Verneuil en Halatte

France

${ }^{4}$ Récepteurs de l'Estradiol et Destinée cellulaire, UMR CNRS 6026, IFR 140,

Université de Rennes 1 ,

Rennes, France

*Present address:

University of Liège

Giga Neurosciences

1 avenue de l'Hôpital

B-4000 Liège, Belgium

Address for correspondence:

Dr. Olivier Kah

UMR CNRS 6026

Campus de Beaulieu

35042 Rennes cedex

Rennes, France

Phone: +33-2 232367 65; Fax: +33-2 232367 94; olivier.kah@univ-rennes1.fr 


\begin{abstract}
Unlike that of mammals, the brain of teleost fish exhibits an intense aromatase activity due to the strong expression of one of two aromatase genes (aromatase A or cyp19ala and aromatase B or cyp19alb) that arose from a gene duplication event. In situ hybridization, immunohistochemistry and expression of GFP (green fluorescent protein) in transgenic $\operatorname{tg}(\mathrm{cyp} 19 a 1 b$-GFP) fish demonstrate that aromatase B is only expressed in radial glial cells (RGC) of adult fish. These cells persist throughout life and act as progenitors in the brain of both developing and adult fish. Although aromatase B-positive radial glial cells are most abundant in the preoptic area and the hypothalamus, they are observed throughout the central nervous system and spinal cord. In agreement with the fact that brain aromatase activity is correlated to sex steroid levels, the high expression of cyp19alb is due to an auto-regulatory loop through which estrogens and aromatizable androgens up-regulate aromatase expression. This mechanism involves estrogen receptor binding on an estrogen response element located on the cyp19a1b promoter. Cell specificity is achieved by a mandatory cooperation between estrogen receptors and unidentified glial factors. Given the emerging roles of estrogens in neurogenesis, the unique feature of the adult fish brain suggests that, in addition to classical functions on brain sexual differentiation and sexual behavior, aromatase expression in radial glial cells could be part of the mechanisms authorizing the maintenance of a high proliferative activity in the brain of fish.
\end{abstract}

Key words: aromatase, cyp19a1b, estrogen synthase, radial glial cells, estrogen receptors, androgens, neurogenesis, sexual behavior, neurosteroids 


\section{Introduction}

The cytochrome P450 aromatase is the only enzyme permitting the conversion of C19 androgens, such as testosterone (T) or androstenedione, into C18 estrogens, estradiol (E2) and estrone, respectively. Estradiol was first acknowledged for playing a key role in reproductive functions, but the spectrum of estrogenic actions is constantly enlarging and now covers effects on the cardiovascular system, the mineralization of the bones, the adipose tissue, the immune system or the central nervous system. Estradiol signaling is also central for the issue of endocrine disruptors given the promiscuity of the estrogen receptors. Originally thought to be produced only by the gonads, estrogens are now acknowledged to bei synthesized in several other organs due to extragonadal expression of aromatase. One can thus appreciate that, given these multiple and crucial roles of estradiol (E2) in different organs, aromatase is integral to the development and functioning of many E2 target tissues, in particular of the brain.

Fifty years ago the first article appeared showing that steroids given prenatally have organizational effects on the brain, that will impact the subsequent behavioral response to sex steroids in adults [1]. This seminal study had a profound influence on the scientific community and led to the so-called "aromatization hypothesis" according to which testosterone produced by the embryonic testis is aromatized within the brain to irreversibly masculinize some specific brain regions [2]. Since these early days, brain aromatization has received considerable attention and it is now believed that estrogen produced in the brain exert multiple actions on a large set of functions, many of which are not necessarily linked to reproduction. The reader is referred to many excellent reviews dealing with different biochemical, neuroanatomical and functional aspects of brain aromatase in vertebrates $[3 ; 4$; $5 ; 6 ; 7 ; 8 ; 9 ; 10 ; 11 ; 12 ; 13 ; 14 ; 15 ; 16]$. 
Brain aromatization occurs in all classes of vertebrates including teleost fish [7; 17]. Teleost fish correspond to a very large group of actinopterygian fishes that encompasses around 30,000 species. Thus, teleosts are of high importance in terms of biodiversity, source of proteins and animal models. As documented below, teleost fish exhibit a number of very unique features that make them quite intriguing with respect to brain aromatization. This review intends to synthesize the rapidly accumulating information on the activity, expression, regulation and functions of brain aromatase in teleost fishes and will complement that already existing $[7 ; 18]$.

\section{1- Aromatase activity in the brain of fish is higher than in other vertebrates}

\section{1 - High aromatase activity in the brain of teleosts}

In 1978, Gloria Callard published the first paper showing that the brain of teleost fish, exhibits high aromatase and 5 $\alpha$-reductase activities [19]. A few years later, the same laboratory showed in adult goldfish (Carassius auratus) and toadfish (Opsanus tau) of both sexes, that brain homogenates incubated with $\left[{ }^{3} \mathrm{H}\right]$-androstenedione produced exceptionally large amounts of estrogens. This aromatase activity was particularly elevated in the pituitary and various forebrain regions, especially the hypothalamus and preoptic area [20]. The authors concluded that "high levels of aromatase in the neuroendocrine tissues of teleosts recommend them as animal models for further studying the enzyme, its regulation, and its role in governing androgen-dependent responses in central targets" [20].

This seminal discovery stimulated intensive research in fish, yet, until the last few years, most of this research remained focused on aromatase activity and its regulation over the sex cycle of different species. Studies in Atlantic salmon, stickleback, African catfish European sea bass and the peacock blenny all confirmed the elevated aromatase activity, especially in the forebrain (tel- and diencephalon) and the pituitary $[21 ; 22 ; 23 ; 24 ; 25 ; 26 ; 27$; 
28; 29; 30; 31]. In sea bass (Dicentrarchus labrax), for example, aromatase activity was measured in different tissues using an optimized tritiated water assay [30]. In adult fish entering the reproductive season, aromatase activity was highest in the brain $(2.04 \pm 0.4$ $\mathrm{pmol} / \mathrm{mg} \mathrm{prot} / \mathrm{h}$; mean $\pm \mathrm{SEM})$, followed by the ovary $(0.59 \pm 0.1)$ and was detectable in visceral fat $(0.21 \pm 0.05)$, liver $(0.08 \pm 0.009)$, and head kidney $(0.03 \pm 0.004)$ [30]. Aromatase activity was negligible in the rest of the tissues tested: heart, testis, muscle, and spleen.

\section{2- Distribution of brain aromatase activity}

Using microdissections or punches on brain sections, some studies very accurately documented the distribution of aromatase activity $[22 ; 24]$. In the three-spined stickleback, (Gasterosteus aculeatus), highest aromatase activity was found in the diencephalon, particularly in the periventricular hypothalamic region containing the nucleus preopticus, in the area containing the nucleus lateralis tuberis, and in the pituitary [22]. The most detailed study was performed in the African catfish (Clarias gariepinus), in which aromatase activity was calculated using the tritiated water assay on punches of frozen sections. The highest activity (3.7 pmol/mg tissue/hour) was detected in the preoptic area, while the ventral hypothalamus, including the nucleus lateralis tuberis and the nucleus recessus lateralis showed slightly lower activity (2.5 pmol/mg tissue/hour). This was similar to what was found in the most rostral part of the telencephalon, the optic tectum and torus semicircularis $(2.3$ $\mathrm{pmol} / \mathrm{mg}$ tissue/hour). A moderate aromatase activity was observed in the remaining parts of the brain, except the cerebellum and hindbrain, in which aromatase activity was hardly detectable [24]. Similarly, in the European sea bass, aromatase activity was found in the olfactory bulb, telencephalon, and hypothalamus (range: $2.6-16.2 \mathrm{pmol} / \mathrm{mg} \mathrm{prot} / \mathrm{h}$ ), as well as the pituitary gland $(6.2-9.3 \mathrm{pmol} / \mathrm{mg}$ prot/h), while lower activity was noted in the optic tectum, cerebellum, and medulla [30].

\section{3- Seasonal variations in aromatase activity}


The first studies on brain aromatase activity in goldfish already pointed out naturally occurring variations during seasonal reproductive cycles, suggesting that sex steroids could modulate this activity. In the goldfish, seasonal variations in aromatase were found to be particularly notable in the anterior hypothalamus/preoptic area of female fish, exhibiting a peak in April and May, corresponding to the reproductive season in goldfish. The levels were six times higher than those found during the period of reproductive inactivity. Interestingly, the pituitary aromatase activity was not correlated with the sex cycle [32]. Similar observations were made in several species, notably in the Atlantic salmon [25; 27], stickleback $[21 ; 26]$ and European sea bass in which a strong correlation between sex steroids, notably testosterone, and aromatase activity was also observed [29].

In Atlantic salmon, the highest aromatase activity was found in the telencephalon and diencephalon. In both regions, activity was higher in mature males than in immature males [25]. Still in Atlantic salmon, castration caused a reduction in brain aromatase activity while testosterone treatment of castrated males increased it. In contrast, 11-ketoandrostenedione, a non-aromatizable androgen, did not have any effect [27]. Similar data were obtained in the stickleback in which aromatase activity in the area containing the preoptic region was dramatically higher in sham-operated males than in gonadectomized ones or in the initial controls. There was no effect of gonadectomy in the other studied regions, such as the mediobasal hypothalamus, the inferior lobes or the thalamus $[21 ; 26]$.

In the European sea bass, brain aromatase activity dramatically changed during the reproductive cycle. Maximum average values were obtained at the time of the spawning season. The peak in brain aromatase activity was preceded by two and one months by the peak of plasma testosterone and the peak of the gonadosomatic index, respectively (Figure 1) [30].

1.4-Male-female differences in aromatase activity in the brain of fish 
There is little information regarding sex differences in aromatase activity in the fish brain. In the male medaka, high levels of activity are localized in sections containing the preoptic area (63-75 fmol/hr) and lower levels in the different nuclei of the ventromedial hypothalamus $(<25 \mathrm{fmol} / \mathrm{hr})$, while the inverse situation was observed in females, $85-80$ $\mathrm{fmol} / \mathrm{hr}$, in the hypothalamus and variable levels (23-70 fmol/hr) in the preoptic area [33]. In one-year-old juvenile European sea bass completing the process of gonadal sex differentiation, brain aromatase activity $(0.63 \mathrm{pmol} / \mathrm{mg}$ prot $/ \mathrm{h})$ was lower than in first time spawners and similar in both sexes. In contrast, in mature animals aromatase activity was much higher in spawners $(6.52 \mathrm{pmol} / \mathrm{mg} \mathrm{prot} / \mathrm{h})$, and males showed an overall higher $(24 \%)$ activity than females, depending on the brain regions [30]. In the plainfin midshipman, differences in the aromatase activity in the hindbrain vocal control region were observed between males and females, and also between males with different reproductive tactics [31].

\section{2 - Two aromatase genes in teleost fish}

While estradiol is found in all vertebrates, its occurrence in invertebrates is not established and recent data claim that vertebrate steroids do not exist in lophotrochozoans, ecdysozoans, or cnidarians. It is thus believed that steroidogenic cytochrome P450 enzymes, including the aromatase gene, descend from those that detoxify xenobiotics [34]. In most gnathostomes, there is a single copy of the CYP19A1 gene. This gene has a complex structure with multiple 5'untranslated exons, each of which is associated with a different promoter driving the tissue-specific expression of the gene $[35 ; 36]$. Although the existence of a single gene was thought to be the rule in mammals, pigs, peccaries and other suiformes have two or more genes resulting from duplication of a common ancestor [37; 38]. In contrast to tetrapods, most teleost fish have two aromatase genes.

\section{1 - Two cyp19a1 genes and two P450 aromatase proteins in fish}


The teleost lineage is well known for exhibiting tremendous variations in genome organization due to a combination of different reasons. One of these reasons is the existence of a third round of whole genome duplication that would have occurred during the teleost emergence [39]. As a result of this so called "3R duplication", fish have many duplicated genes, the fates of which vary greatly according to the gene and from one order to the other. However, supporting a 3R duplication event, many teleost fish that have been studied in detail so far exhibit two aromatase genes, cypal9ala and cyp19alb. Aromatase in fish was first cloned from the trout ovary [40]. However, the existence of two genes in a teleost fish was first reported in goldfish after the discovery that a full-length aromatase complementary DNA (cDNA) isolated from a goldfish brain cDNA library was strongly expressed in the brain, but not in the ovary [41]. In addition, a 1.9-kb cDNA encoding a protein of 518 amino acids was isolated from the goldfish ovary. This latter sequence shared high sequence identity (68-72\%) with ovarian aromatases of other fish species, but only $62 \%$ identity with the brain-derived goldfish form. According to Southern blotting and PCR-restriction analysis of genomic DNA, a single locus generates brain aromatase, whereas one or two different loci encode the ovarian form (cyp19ala) [41]. Since this important finding, two genes encoding two aromatase forms were found in many teleosts, but not in all species.

The two genes encountered in teleosts are now officially named cyp19ala and cyp19alb, but have been given different names before the establishment of the current nomenclature: cyp19ala (cyp19a, aromatase A, AroA, CYP19A, P450aromA) and cyp19a1b (cyp19b, aromatase B, AroB, CYP19B, P450aromB). They generate two structurally and functionally different isoforms that, in this review, will be referred to as aromatase A and aromatase B, mostly expressed in the ovary and brain, respectively. Two such genes were identified in an increasing number of species including the rainbow trout $[40 ; 42]$, the zebrafish [43; 44], the Nile tilapia [45], the European sea bass [46], the protogynous wrasse, 
Halichoeres tenuispinis [47], the killifish Fundulus heteroclitus [48], the orange-spotted grouper Epinephelus coioides [49] and the ricefield eel Monopterus albus [50]. However, importantly, so far only one gene has been retrieved from either the European or the Japanese eel. This unique gene is expressed in both the gonads and the brain and its expression submitted to alternative usage of different promoters [51; 52].

A phylogenetic analysis of cyp19al of fish (Figure 2) clearly shows that fish aromatases segregate in an "ovarian" cyp19ala branch and a "brain" cyp19alb branch. The eel sequence seems to be closer to the brain branch as already shown by previous studies [51; 52]. Eels belong to the order Elopomorphs, considered to be an early branching teleost order. The retention of both genes after the duplication event, followed by what seems to be a partition of functions between cyp19ala and cyp19a1b, indicates that a conservation pressure was exerted on both of them, stressing out their respective importance in both tissues.

In zebrafish, the cypa19ala and cyp19alb loci are located on distinct chromosomes, LG18 and LG25. The cyp19ala and cyp19alb were mapped to the proximal portion of the lower arm of LG18 and the upper arm of LG25, respectively (Figure 3) [53]. As detailed below, the zebrafish cyp19alb promoter is probably the most documented [41; 43]. It is likely that following the $3 \mathrm{R}$ whole genome duplication, the two copies of the cyp19a1 gene underwent a progressive partition of function.

\section{2- Characteristics of brain aromatase versus gonadal aromatase}

Because most studies on aromatase activity were performed before the discovery of two aromatase forms in fish (see above), information comparing the properties of aromatase A versus aromatase B is scarce. In the goldfish, Chinese hamster ovary cells were stably transfected with brain- and ovary-derived cDNAs to compare the properties of the two aromatase forms. Although $\mathrm{Km}$ values were similar at around $2.5 \mathrm{nM}$ (for androstenedione) and $1.1 \mathrm{nM}$ (for testosterone), the $\mathrm{Vm}$ was higher in the brain than in the ovary [54]. In the 
sea bass, the tritiated water assay using $\beta\left[{ }^{3} \mathrm{H}\right]$-androstenedione was carefully validated to measure aromatase activity in crude homogenates and microsomes [29]. Within the range of temperatures appropriate for sea bass, $10-30{ }^{\circ} \mathrm{C}$, aromatase activity varies in a linear fashion. The $\mathrm{Km}$ from brain and ovarian homogenates obtained from the same fish during the spawning season values were $7.3 \mathrm{nM}$ vs. $4.6 \mathrm{nM}$ respectively, but differences between the two tissues were not significant. According to this study, and similar to goldfish, sea bass aromatase has a higher affinity for androstenedione and this value is notably higher than what is reported for other fish or mammalian aromatases. The maximum reaction rate (Vmax 7.8 $\mathrm{pmol} / \mathrm{mg}$ protein/hr) was four-fold higher $(\mathrm{P}<0.001)$ in the brain than in the ovary Vmax $(2.1$ $\mathrm{pmol} / \mathrm{mg}$ protein/hr). Consistent results were found using purified microsomes [29].

\section{3- Expression of aromatase $B$ in the brain of adult fish is restricted to radial glial cells}

\section{1- Expression of cyp19a1b in the brain of fish}

The first attempt to localize cyp19alb-expressing cells was performed in goldfish, using an antibody against aromatase partially purified from human placenta. In this study, labeled cells having a neuronal appearance were found in regions associated with reproductive control such as the preoptic or the hypothalamic nuclei [55]. However, only a low number of aromatase immunoreactive cells were labeled, which was not consistent with the high aromatase activity and transcript levels described in the brain of goldfish.

It was only in 2001 that Forlano and colleagues established, for the first time, a convincing cellular localization of aromatase expressing cells using in situ hybridization and immunohistochemistry of brain aromatase. This was done in the plainfin midshipman (Porichthys notatus), a Batrachoidiforme toadfish $[7 ; 56]$. The plainfin midshiman is an interesting model of fish exhibiting a complex spawning behaviour in which two male morphs compete for a female. One of these morphs, type I builds and guards nests while producing 
sounds ("humming") to acoustically court females. Large sonic muscles that are attached to the walls of the swim bladder produce such sounds and these muscles are controlled by a sonic motor nucleus located at the junction between the hindbrain and the spinal cord. In this fish, it was first shown that aromatase transcripts were consistently detected in the ventricular regions of the hindbrain, the midbrain, and forebrain $[7 ; 56]$. In the sonic motor nucleus, cyp19a1b mRNA levels expression levels were elevated but not greater than in the preoptic area or the telencephalon. In the midbrain, cyp19alb transcripts were localized between the medial boundary of the torus and the valvula [56]. Along the third ventricle of the hypothalamus, cyp19a1b mRNAs were also detected at high levels, whereas there was no hybridization signal in the optic tectum and the torus semicircularis. Finally, in the telencephalon, the highest hybridization signal was detected along the periventricular layer of the preoptic area. In addition, transcripts were also reported in most ventricular layers, notably in the ventral nucleus of area ventralis, in the ventral and medial olfactory bulb, but also in the periphery of the telencephalic hemisphere [56].

These data were confirmed by immunohistochemistry using an antibody raised against a consensus sequence of teleost brain aromatases showing a protein localization that significantly overlapped with that of the messenger. Many aromatase B-immunoreactive cells were found in the hindbrain, the midbrain, the diencephalon and forebrain, always in the periventricular regions, notably along the third ventricle of the hypothalamus, the periventricular layer of the preoptic area, the ventral nucleus of area ventralis, the ventral and medial olfactory bulb and in the periphery of the telencephalic hemisphere [56]. Very interestingly, Forlano and colleagues showed that aromatase B was expressed in a peculiar cell type, the radial glial cells. Indeed, consistent with the unique morphology of radial glial cells $[57 ; 58]$, aromatase B-positive cells exhibit small cell bodies localized along the ventricle and extend long cytoplasmic fibers/processes that reach the basal surface of the brain 
[7; 56]. Moreover, aromatase B distribution overlapped in some regions with that of GFAP (glial fibrillary acid protein), a radial glia marker in fish [59], best known for being expressed in astrocytes in mammals [56]. It was also shown that aromatase B-immunoreactive cells did not correspond to neurons identified on the basis of immunoreactivity to the nuclear neuronal protein $\mathrm{Hu}[56]$.

Such results were rapidly confirmed in several species, including the rainbow trout in which in situ hybridization showed that cyp19alb transcripts were strongly expressed in the periventricular layers of the anterior brain, in the telencephalon, diencephalon and mesencephalon, in a way similar to that described in the plainfin midshipman, with stronger hybridization signal in the hypothalamus and preoptic area, but also in the pituitary gland [60]. Figure 4 shows the extremely high expression of cyp19alb mRNAs in the forebrain of an adult female rainbow trout. A weaker hybridization signal was also observed in the periventricular layer of the torus semicircularis, the optic tectum and around the fourth ventricle. Antibodies raised for aromatase B detection in the plainfin midshipman were successfully used in the rainbow trout [60], in which abundant aromatase B-immunoreactive cells were detected in the different lobes of the pituitary and in cells bordering the ventricles in the telencephalon and ventral diencephalon, with a very high expression in the preoptic area and the hypothalamus. These aromatase B-immunoreactive cells exhibit a small ovoid nucleus localized along the ventricles, a short end foot directed toward the ventricle and a long radial process ending at the pial surface [60]. Aromatase B-positive cells were observed in the torus semicircularis and also in the optic tectum where the cell bodies were localized in the ependymal wall and the long processes cross the parenchyma throughout all tectal layers. This latter data is in contrast with data concerning the plainfin midshipman in which no aromatase was observed in the tectum [56]. 
In zebrafish, brain aromatase distribution has been extensively studied using in situ hybridization, immunohistochemistry and GFP (green fluorescent protein) expression driven by the cyp19a1b promoter, these data consistently show the expression of cyp19alb in radial glial cells $[18 ; 61 ; 62 ; 63 ; 64 ; 65]$. The aromatase B mRNA expression pattern is very similar to that reported in the plainfin midshipman. Indeed, cyp19alb transcripts were detected in the periventricular layers but also in the brain parenchyma of the caudal olfactory bulbs, the ventral telencephalon, the preoptic area, the hypothalamus, and in the anterior and posterior lobes of the pituitary [65]. Very surprisingly, in contrast with the rainbow trout, cyp19alb mRNAs appeared to be exported in zebrafish within the radial processes and to accumulate in the end feet at the periphery of the brain $[18 ; 65]$.

Figure 5 shows the comparative distribution of aromatase B-immunoreactive cells according to Menuet at al. (2005) [62], aromatase B messengers and cyp19alb-GFP expressing cells [66]. Two antibodies were generated against zebrafish aromatase B, one against a 15 amino acid sequence and the other against a partial recombinant protein $[18 ; 62]$. Both antibodies yielded similar data overlapping perfectly with the distribution of the messengers. Similarly, as shown in Figure 5, there is a perfect overlapping of the localization of aromatase B-expressing cells and that of cells expressing GFP driven by $2.8 \mathrm{~kb}$ of the cyp19alb promoter, further indicating that the transgenic $\operatorname{tg}($ cyp19alb-GFP) recapitulates very well cyp19a1b expression [66].

Data indicating expression of aromatase B in radial cells were also obtained in the pejerrey (Odontesthes bonariensis) [67], confirming the expression of cyp19alb mRNAs in the periventricular layers of the preoptic area, the hypothalamus, the optic tectum and the ependymal layer of the fourth ventricle. In the bluehead wrasse (Thalassoma bifasciatum) aromatase B-immunoreactivity appeared to be present in glial cell populations, and was found in the dorsal and ventral telencephalon, the preoptic area of the hypothalamus, and the lateral 
recess of the third ventricle, among other brain areas [68]. Table 1 summarizes relative distribution and amount of aromatase B- immunoreactivity in different regions of the brain of teleost fish species studied to date.

\section{2- Expression of aromatase B protein is mostly restricted to radial glia}

The localization of aromatase B in radial glial cells of adult fish is quite intriguing, given that aromatase in bird and mammals is mainly found in neurons [12; 69]. In the male adult rodent, the aromatase messengers are well expressed in the encapsulated bed nucleus of the stria terminalis, the medial preoptic nucleus, the ventromedial nucleus, the medial amygdala and the cortical amygdala [70]. However, many cells with lower expression also exist in the hippocampus and the dentate gyrus, as well as in distinct layers of the neocortex [70]. Studies aiming at using immunohistochemistry in mammals have been hampered by the difficulty in obtaining antibodies working on mammalian tissues [12]. In contrast, antibodies to human placental aromatase or quail aromatase proved very efficient in locating aromatase in the brain of birds, where the aromatase protein was found mainly in neurons including the axons and terminals $[71 ; 72]$. Additionally, aromatase distribution in the songbird brain was thoroughly delineated using an avian specific antibody [73]. Nevertheless, in a limited number of studies, aromatase was reported in astrocytes, notably in the cortex of human or monkey [74; 75]. In mammals, radial glial cells are believed to disappear at the end of embryogenesis, but aromatase was observed in radial glia in the developing mouse cortex [76]. In birds, radial glial cells persist in many parts of the adult brain. They normally do not express aromatase but, after a mechanical lesion in the zebra finch cortex, aromatase immunoreactivity appears in radial glial cells facing the lesion, while no staining is seen in other ipsilateral regions or in the contralateral side [77].

In fish, there is strong evidence that aromatase B is expressed virtually only in radial glial cells. An exception is the presence of aromatase B positive neurons in the peripheral 
ganglion neurons that projects into the hair cells in the inner ear of the plainfin midshipman, the [78]. Double stainings with a neuronal marker such as $\mathrm{Hu}$ or acetylated tubulin demonstrated that aromatase immunoreactive cells do not express neuronal markers [56; 64]. Not only do aromatase expressing cells have the typical phenotype of glial cells [79; 80], but they also express radial glia markers such as GFAP ([56; 81], vimentin [81], or brain lipid binding protein (BLBP) [66;81]. Figure 6 shows the virtually perfect overlapping between the distributions of $c y p 19 a 1 b$ and that of the radial glial marker BLBP.

Therefore, the available information that for the moment concerns only a few species, indicates that the brain of adult fish is unique in expressing aromatase B in radial glial cells and not in neurons, except in the ganglion cell population innervating the inner ear of the midshipman $[7 ; 56]$. The reasons for this intriguing cell specific expression are not fully understood, but some progress has been recently made with respect to the regulation of cyp19alb expression, mostly in zebrafish.

\section{4 - Regulation of cyp19a1b expression in the brain of fish}

\section{1 - Promoter structure of the cyp19a1b gene}

The structure of the cyp19alb genes has been examined in detail in some species including zebrafish, catfish, goldfish, medaka, tilapia and fugu. In the zebrafish for instance, a TATA box, a consensus ERE (-348bp) and a half ERE (-293bp) were found within the 500bp of the in the cyp19a1b proximal promoter. Additional potential binding sites notably include a consensus nerve growth factor inducible-B protein (NGFI-B)/Nur77 [43; 82], an arylhydrocarbon receptor (AhR) recognition site, c-AMP responsive elements, a chicken ovalbumin upstream promoter-transcription factor (COUP) and Ptx-1binding sites [83]. Figure 7 shows an alignment of the promoters of six different fish species and clearly highlights the perfect conservation of the ERE throughout evolution, most likely indicating a 
very important mechanism of regulation $[82 ; 83 ; 84 ; 85 ; 86 ; 87 ; 88]$. In contrast, surrounding the conserved ERE, a number of potential binding sites that differ from species to species have been reported, but their functionality has not been established.

It is also interesting to observe the conservation of the genomic structure and particularly the consistent presence of an untranslated exon in cyp19alb mRNA. This conservation of the intron/exon junctions most likely reflects the existence of important splicing events. Alternative splicings generating different 5'UTR have been identified in the Nile tilapia [86] and in the rainbow trout [89]. In the Nile tilapia, three different transcripts were identified, the longest including a short un-translated exon (43 bp long) that is $1227 \mathrm{bp}$ from exon II.

\section{2 - Transcriptional regulation of the zebrafish cyp19a1b promoter}

Only a few studies have addressed the regulation of the cyp191b gene at the promoter level. This is most likely due to the strict cell-specificity of this promoter that remains inactive in most cell lines. In zebrafish, it was shown that the high specific expression of the cyp19alb gene in radial glial cell as observed in vivo could be also obtained in vitro using glial or neuro-glial cell lines [62]. The characterization of the underlying mechanisms and the identification of the cis-regulatory elements involved in glial cell specific expression of the cyp19alb gene were thus studied using classical transfection approaches based on the reporter gene.

\subsection{1 - Regulation of cyp19alb by steroid hormones}

In line with the well-documented effects of steroids (estrogens and aromatizable androgens) on brain aromatase activity, the analysis of cyp19alb genes from several teleost species underlined the presence of a well-conserved estrogen-responsive element (ERE) in the proximal promoter sequences (Figure 7). This ERE is located at $-300 /-350 \mathrm{bp}$ of the transcription initiation start site. In addition, several putative cis-regulatory elements 
including potential androgen-responsive elements (ARE) are found within the $3000 \mathrm{bp}$ proximal promoter. Transfection assays with different fragments of the zebrafish cyp19alb promoter (up to $3000 \mathrm{bp}$ ) fused to luciferase revealed that, in the presence of the estrogen receptor, E2 failed to activate a cyp19alb-luciferase reporter in most cell lines, indicating that E2-regulation of cyp19a1b depends on the cell context (Figure 8). Indeed, while no or very weak activity of the promoter following E2 treatment was observed in cell lines such as HeLa, CHO-K1, undifferentiated PC12 (PC12U), or NGF-differentiated PC12 (PC12D), a dramatic activity of the reporter was observed in cell lines providing a glial (251-MG cells: human astrocytes) or neuroglial context (P19 mouse embryonic carcinoma cells differentiated by retinoic acid) (Figure 8A). Deletions or mutations studies indicated that integrity of the ERE located at $-348 \mathrm{bp}$ is a prerequesite for estrogenic regulation. In comparison, a classical ERE$t k$-luciferase construct containing a consensus ERE was stimulated equally by E2 in all cell lines (15 to 25 fold induction; Figure 8B). These data indicate that the cyp19alb promoter is extremely sensitive to estradiol, but only in specific cell contexts.

Several previous studies indicated that the cyp19alb gene is also up-regulated in vivo by certain androgens, notably testosterone. Despite the presence of putative androgen responsive elements (ARE), transfection experiments showed that neither androgen receptor nor the potential ARE are required for the stimulation of cyp19alb by androgens (testosterone: T and 5alpha-dihydrotestosterone: DHT). In fact, it was recently shown that the androgenic regulation is mediated through ER binding on the ERE located at $-348 \mathrm{bp}$. The effect of testosterone is indeed due to aromatization into E2, whilst the effect of DHT involves conversion into 5 alpha-androstan-3 beta, 17 beta-diol, a known metabolite of DHT which directly interacts and activates ERs [63]. In mammals, it has long been established that DHT can be metabolized into either 5 alpha-androstan-3 alpha, 17 beta-diol or 5 alphaandrostan-3 beta, 17 beta-diol [90]. In addition, 11-keto-testosterone, the major androgen 
identified in male fish with no possibility of conversion into estrogenic compounds, fails to up-regulate the cyp19alb promoter in vivo and in vitro [63]. This explains why, in vivo or in vitro, the up-regulation of cyp19alb by $\mathrm{T}$ and DHT is blocked by the pure anti-estrogen ICI 182,780 [63]. Whether the situation is similar in all fish remains to be investigated.

\subsection{2 - Control of the cell-specific expression of cyp19alb in radial glial}

cells

Given the above-mentioned regulation of cyp19alb through ER, it is surprising that cyp19alb expression is restricted to radial glial cells and that no aromatase B is detected in neurons strongly expressing ER in the brain parenchyma [91]. In agreement with the abovementioned results, this indicates that ERs are not sufficient to drive cyp19alb expression in the brain of fish in the presence of estrogens. In fact, it was shown that the zebrafish cyp19alb promoter contains a complex regulatory element located between -277 and -257 bp from the initiation start site (Figure 9A). This short sequence of $20 \mathrm{bp}$, referred to as GxRE, seems to play an important role in the cell specific and E2-regulation of the gene [92]. Indeed, deletions or mutations in this GxRE sequence caused strong reduction (80\%) of the E2dependent induction, indicating that the ERE is necessary, but not sufficient for full estrogenic activation of the cyp19b in the glial context. This also suggests that the GxRE may recruit specific transcription factor(s) that could act in synergy with the ERs. Several studies reported cross-talk between ER and other nuclear receptors or transcription factors [93; 94; 95; 96; 97]. A common characteristic of all these cross talks between ER and other transcription factors is that a direct physical interaction is often required implying that the ER structure, and then the ER subtype, is determinant. The results so far indicate that the GxRE acts in synergy with ER to enhance E2-stimulation independently of the specific ER subtype or ER phosphorylation site. Importantly, the GxRE motif can act as an autonomous cis element, increasing E2-stimulation exclusively in the glial cell context [92]. In contrast, 
addition of the GxRE did not cause E2-enhancement of an ERE-reporter gene in non-glial cell lines. Thus, if the GxRE region recruits transcription factor(s) able to cooperate with ER during E2-dependent induction, it is likely that these factors are specific to glial cells. To test this hypothesis gel mobility shift assays were performed using the GxRE as probe and whole cell extracts from different cell lines [92]. Figure 9B shows that the GxRE is capable of recruiting transcription factor(s) specifically expressed in glial or neuroglial cells, but not in other cell contexts. These data confirmed the hypothesis according to which these DNAbounds transcription factor(s) can synergistically cooperate with ER to regulate the cyp19a1b gene. Moreover, the GxRE motif contains the core sequence AGGTCA that is acknowledged to recruit different types of nuclear receptors.

It is known that the liver receptor homologue 1 (LRH-1), an orphan nuclear receptor, modulates the CYP19a1 gene expression in testis via a DNA sequence containing the AGGTCA motif [98]. Additionally, LRH-1 is strongly expressed throughout the mouse brain suggesting important roles for this factor in brain functions. Interestingly, in the medaka (Oryzias latipes), lrh-1 acts as an activator of the cyp19alb gene [99]. Moreover lrh-1 mRNAs are co-localized with cyp19alb mRNAs in the brain of medaka, highlighting that LRH-1 could be a good candidate to cooperate with ER on the zebrafish cyp19alb promoter. As some other members of the nuclear receptor family, LRH-1 probably plays an important role, as a transcription factor, in steroid hormone production [100]. A recent study in humans showed that LRH-1 induces the expression of steroidogenic enzymes, including CYP17, in mesenchymal stem cells and accompanies their differentiation into steroid hormoneproducing cells [101].

Data on cyp19alb regulation in zebrafish are quite interesting since the possibility exists that part of the mechanisms driving expression of aromatase in radial glial cells of fish may also be relevant to explain de novo aromatase expression in radial cells or astrocytes 
following lesions in other models. Although the GxRE sequence seems very important in zebrafish, this sequence does not appear to be totally conserved in all fish species. The current working hypothesis is that the glial-specific expression of the cyp19alb gene results from a combination of different transcription factors acting on several cis-regulatory elements including the GxRE in zebrafish, but the combinatorial expression pattern could have been modified across evolution. In the near future, attention should be focused on identifying the combination of factors that regulate cyp19alb expression in the zebrafish brain and on developing chromatin immunoprecipitation assays to clarify whether these factors interact directly with their binding sites in the cyp19alb promoter of zebrafish.

\subsection{3 - Effects of endocrine disruptors on cyp19alb expression}

The presence of a functional ERE and prediction of a dioxin responsive element (DRE, also called aryl hydrocarbon responsive element, AhRE) in the cyp19alb proximal promoter of zebrafish led to the assumption that some endocrine disrupting chemicals (EDCs), such as estrogen- and dioxin-like, might interfere with the expression of the cyp19b gene $[102 ; 103]$. Consequently, the cyp19b gene in zebrafish may constitute a good model to study the molecular mechanisms of action and possible cross talk of estrogen- and dioxin-like EDCs.

In agreement with studies showing that xeno-estrogenic endocrine disruptors affect cyp19alb expression, studies in zebrafish have demonstrated that ethynilestradiol (EE2), estrone (E1), genistein and zeralenol, individually or in combination are able to modulate cyp19alb gene transcription at its promoter level. Transfection studies of the cyp19albluciferase reporter in the presence of ER in U-251 cells clearly indicated that modulation of cyp19a1b gene transcription by these chemicals requires direct interaction between ER and the functional ERE within the cyp19alb promoter. Given its sensitivity to estrogens, the 
cyp19alb gene is thus an outstanding biomarker for xeno-estrogens exposure in vivo and in vitro [104].

In addition, in vivo studies showed that dioxin-like compounds decrease estrogenstimulation of cyp19alb gene expression in zebrafish and subsequently negatively impacting fish development and reproduction $[105 ; 106]$. Dioxin significantly reduces the E2upregulation of cyp19alb gene transcription, but dioxin effects are totally independent of the predicted DRE, located at $-450 \mathrm{bp}$ from the initiation start site, in the proximal promoter of the cyp19alb gene [103; 107]. Importantly, dioxin effects could be fully abolished by using antagonistic molecules for the aryl hydrocarbon receptor (AhR) and ER, indicating involvement of both AhR and ER in these processes. These dioxin actions observed in the zebrafish cyp19a1b promoter [103] are in line with previous studies on human AhR [95]. In fact, the AhR agonists were reported to activate a reporter gene containing an ERE, without binding directly to ERs or affecting ER expression levels. However, when this promoter is activated by E2, dioxin has an antagonistic effect. The presence of both receptors, AhR and ER are necessary for dioxin actions that imply physical interactions between AhR and ER as demonstrated by co-immunoprecipitation. These studies suggest an original mechanism of activation of the ER in the absence of estradiol since ligand-activated AhR is able to cooperate with the ER to activate the transcription of the cyp19alb promoter. However in the presence of E2, the AhR ligands, including dioxin behave as partial antagonist on cyp19alb transcription. Altogether, these studies highlight the importance of estrogen concentrations that might determine the estrogenic or anti-estrogenic effects elicited by AhR ligands [103].

\section{3 - Early expression of cyp19a1b during development}

Given the sensitivity of the cyp19alb gene to estrogen-or dioxin-like compounds, it is important to understand the mechanisms regulating aromatase expression during early developmental stages. Studies by Callard and colleagues (2001) indicated that in zebrafish, 
cyp19ala and cyp19a1b transcripts are already detected in unfertilized eggs. Then, from 1.5 hours post fertilization (hpf), cyp19alb transcripts decrease until $12 \mathrm{hpf}$ (gastrula period), due to the transfer and degradation of maternal mRNAs [84]. At 3 hpf, zygotic transcription starts in zebrafish [108], and aromatase transcripts slowly increase during the segmentation period (from $12 \mathrm{hpf}$ to $24 \mathrm{hpf}$ ). Then, cyp19alb mRNAs strongly increase between 24 to $48 \mathrm{hpf}$ and accumulate until $120 \mathrm{hpf},[61 ; 84]$. Around 20 days post fertilization (dpf), when the gonad is still undifferentiated, the pattern of cyp19alb expression could be clearly segregated into two populations, suggesting a possible association with sex differentiation [109]. However, although this bimodal pattern was confirmed in another study, it was lost at later stages of development; indeed, between $30-50 \mathrm{dpf}$ during the period of sexual differentiation, there is no correlation between aromatase B expression and the gonadal phenotype [110]. It must be pointed out here that, as most fish except some medaka strains [111], zebrafish have no known sex determining gene. This does not allow us to ascertain whether the bimodal population really corresponds to males and females. However, a recent study performed on monosex genetic rainbow trout populations clearly showed that at $35 \mathrm{dpf}$, before the period of gonadal sex differentiation, males have higher levels of cyp19alb mRNA than females. This difference is lost from 50dpf onwards (D. Vizziano, I. Anglade, Y. Guiguen and O. Kah, unpublished).

The comparison of estrogen receptor and cyp19alb expression during early development in zebrafish indicates spatiotemporal relationships between their expression. Whole mount in situ hybridization and quantitative RT-PCR showed a significant increase in the expression of the three estrogen receptors, esrl, esr2a and esr $2 b$, found in zebrafish [112] between 24 and $48 \mathrm{hpf}$. This increase parallels that observed for the cyp19alb gene [63]. It is very likely that the basal expression of cyp19alb is due to estrogen receptor activation since exposure of embryos to the pure anti-estrogen ICI 182,780, dramatically reduces the increase 
of cyp19alb expression between 24 and 120 hdp. Furthermore, there is also a spatial correlation between expression of estrogen receptors, esr $2 b$ and esr $2 a$, in the preoptic area and in the hypothalamus, the regions where cyp19alb mRNAs first appear between 24 and $48 \mathrm{hpf}$ $[61 ; 62]$. The fact that functional estrogen receptors are already present around $24-48 \mathrm{hpf}$ is further reinforced by the fact that exposure of embryos to estrogens or xeno-estrogens at these stages causes a dramatic increase in cyp19alb mRNAs [61;62], aromatase B protein [62] and cyp19a1b-GFP $[61 ; 66]$ expression in the brain.

\section{4- Relationships between estrogen receptors and cyp19a1b localization in the}

\section{brain of fish}

In the brain of fish, aromatase expression is highest in those brain regions with strong expression of estrogen receptors $[112 ; 113 ; 114]$. This is not surprising given that estrogen receptors are most likely to be needed in the vicinity of aromatase-expressing cells, in order to mediate the potential genomic effects of estrogens on surrounding target cells. On the other hand, all aforementioned data indicate that the exceptional expression of aromatase is largely, if not solely, due to the transcriptional effects of ER on the cyp19a1b promoter. One would therefore expect to observe a tight spatial relationship between ER and aromatase expression in the radial glial cells. There are many indications that the strongest expression of cyp19alb is observed in brain regions, notably the preoptic area or the mediobasal hypothalamus, known for their high concentrations of ER mRNAs or protein [18]. However, the formal demonstration that ER are expressed in radial cells is still lacking as all studies addressing this question used in situ hybridization on parallel sections $[60 ; 61 ; 78 ; 115]$. Such studies showed a close relationship, but were not conclusive in terms of estrogen receptor expression in radial glial cells. Nevertheless, in rainbow trout, esra mRNA could be amplified by RT-PCR from glial cell cultures [60]. In the pejerrey, esr1 and cyp19a1b are expressed in cells lining the preoptic recess [115]. In the zebrafish, both esr $2 a$ and $e s r 2 b$ mRNAs are expressed along the 
brain ventricles in many brain regions (F. Adrio and O. Kah, unpublished data). The current assumption is that estrogen receptors are probably expressed at low levels in radial glial cells but, given the high sensitivity of the cyp19alb promoter to estrogens (see section 4.2.1), these levels would be sufficient to up-regulate aromatase B expression in radial cells.

\section{5- Functional significance of aromatase expression in the brain of fish}

It is now clear that the expression of cyp19a1b in the central nervous system of fish is restricted to the radial glial cells. It is also clear that the exceptional aromatase activity is due to the strong induction of the cyp19alb gene by estrogens (or aromatizable androgens) due to a positive auto-regulatory loop through which estrogens, the products of aromatization, stimulate expression of their biosynthetic enzyme. What is really unclear are the potential functions of these estrogens produced locally in the brain. The situation is made even more complex when one contemplates the increasing diversity and complexity of the mechanisms underlying estrogen signaling. Indeed, diverse effects of membrane-mediated receptors have now been added to the classical genomic effects of esr1 and esr2 [116; 117]. These membrane-mediated effects may involve membrane estrogen receptors, such as GPR30, receptors for neurotransmitters, or interactions with growth factors $[118 ; 119 ; 120]$. Such membrane effects are not well documented in teleosts, but there is no reason to assume that they do not exist. Although these different mechanisms are likely to sustain a variety of estrogen effects on target cells, there is little precise information on the nature of such effects in fish.

\section{1- A role for brain aromatase in fish sexual differentiation?}

As stated above, there are many reasons, notably the weak genetic component of sex determination in fish, to assume that the mechanisms of brain sexual differentiation in teleost fish are different to those in mammals. The role of aromatase in sex differentiation has mainly been addressed at the level of the gonads where aromatase in recognized as a pivotal factor 
[121]. The current vision considers that cyp19ala up-regulation is needed to trigger and maintain ovarian differentiation, whereas cyp19ala down-regulation is a sufficient condition for inducing a testicular differentiation [121]. Nevertheless, there is some indication that brain aromatase could have a role in the process of sex differentiation. Indeed, there are an increasing number of studies showing that cyp19alb expression shows a sexually dimorphic pattern early in development and prior to the period of gonadal sex differentiation $[109 ; 115$; $122 ; 123]$. In the zebrafish, at 20 days i.e. before the period of sex differentiation cyp19alb expression exhibits a bimodal profile $[109 ; 110]$ that disappears at later stages but supposedly reflects a sexual dimorphism. In the pejerrey, whose sex determination is dependent on temperature, brain aromatase is more elevated at the male-promoting temperature [115]. In the protandrous hermaphrodite black porgy (Acanthopagrus schlegeli), it was found that steroidogenic enzymes including brain aromatase are expressed at 60 days post-hatching, long before the period of testicular differentiation. The authors conclude that the coordinated increase in the expression of steroidogenic enzyme suggests that estradiol may be locally formed in most parts of the brain. This suggests an important role for brain aromatase in the male sexual differentiation of the brain in the black porgy [123]. Similarly in trout, recent data indicate that neurosteroid production is higher in the brain of males before the period of gonadal morphological differentiation (D. Vizziano, Y. Guiguen and O. Kah et al., unpublished data). All these studies tend to indicate that neurosteroids, and notably neuroestrogens, may be implicated in the male brain differentiation, although this remains to be formally demonstrated. In contrast, cyp19alb expression was not significantly different in a male enriched population of European sea bass, as compared to a female enriched population [122].

Fish are known for exhibiting a wide variety of reproductive strategies ranging from gonochorism to sequential or simultaneous hermaphrodism. Many species change sex during 
their life history. This high plasticity of the phenotypic sex is viewed as an evolutive advantage: animals change sex when this change serves to increase their reproductive values [124]. This implies that if the gonad is bipotential, the brain must also exhibit bipotentiality. In mammals, the brain is irreversibly sexualized during the critical period of development. This is achieved through the brain aromatization of testosterone that masculinizes and defeminizes the brain. In fish, although the brain is sexualized during development in gonochorist species, the sexual orientation can be modified later in life as shown by hormonal manipulations that can induce a complete phenotypic sex change including the appropriate behaviour [125]. According to Kobayashi (2002), the brain bipotentiality is permanent including in gonochorist fish. This is based on the fact that changes in sexual behaviour following hormonal treatment are very rapid suggesting activation of pre-existing mechanisms or structures [126]. The mechanisms underlying these changes are not known. However, the fact that aromatase is expressed in radial glial cells that are progenitors in the brain of fish (see below) and the fact that aromatase expression is modulated by sex steroids, certainly provides the substrate for a modulation of the neurogenic activity by estrogens and androgens. Clearly, theses issues deserve further attention.

\section{2- Aromatase and neuroendocrine effects}

In early studies, a role for brain aromatization of androgens has been demonstrated in the context of the neuroendocrine control of reproduction. For instance, in the brain of the triploid rainbow trout, both estrogens and aromatizable androgens increased salmon GnRH contents. In these animals, which have very low levels of circulating steroids, testosterone is more active than estradiol, probably because of high aromatase activity in the GnRH containing regions [127]. Both steroids were also shown to increase the salmon GnRH contents within the pituitary, which in fish receives a direct GnRH innervation. Similar data were obtained in the African catfish in which testosterone is able to accelerate the 
development of the catfish GnRH system, whereas hydroxy-androstenedione, a nonaromatizable androgen, has only minimal effects [128]. These results indicate that one of the effects of the high testosterone concentrations found in both male and female salmonids during the maturation period is to accelerate the development and maturation of the neuroendocrine circuits.

\section{3-Aromatase and sexual behaviour}

The role of aromatase in sexual behaviour is well established in mammals and birds. The effects of estrogens on sexual behaviour have been categorized into three classes: organizational (irreversible genomic action during ontogeny), activational (reversible genomic action during adulthood) and rapid non-genomic effects. In these models, locally produced estrogens are important for brain maculinization in males (in rodents) and brain defeminization of females (in quails) $[129 ; 130]$. In adults, testosterone produced by the testes is converted into estrogens by brain aromatase, resulting in gene transcription through genomic effects implicating ER. In addition, brain aromatase activity can be modulated in a matter of minutes by calcium-dependent phosphorylation, triggered by variations in glutamatergic neurotransmission. Such rapid changes in aromatase activity affect male sexual behaviour in quail and in mice $[129 ; 130]$.

The role of aromatization in sexual behaviour in fish is also well recognized [125]. In many fish, androgen or estrogen treatment causes a typical male sexual behaviour [125], but the underlying mechanisms are largely unknown. The most detailed information comes from species with alternative male strategies such as the plainfin midshipman [7]. In this species, type I males court females into their nest while type II try to approach the nest to achieve parasitic fertilization. Type I males produce sounds ("humming") using their swim bladder and control these sounds through a sonic motor nucleus that acts on the muscles of the swim bladder and expresses aromatase [56; 78]. During the reproductive season, type II males show 
higher aromatase mRNA in the sonic motor nucleus than type I males or females that do not produce "humming" like vocalization [131]. Consistent with aromatase expression in this motor nucleus, estrogen treatment rapidly increases the duration of vocal output obtained by electrical brain stimulation in both type I and II males and females. While testosterone has a similar effect in females and type II males, its action in females is entirely dependent on the rapid aromatization of testosterone in estradiol [132].

Aromatase has also been implicated in aggressive behaviour in fish. Fish treated with estrogens [133] or exposed to xeno-estrogens [134] show reduced aggressivity. In a sex changing goby, Lythrypnus dalli, it was also shown that socially induced and rapid increases in aggression are inversely related to brain aromatase activity, suggesting that aromatase activity can modulate fast changes in vertebrate social behaviour [135]. Similarly, in the peacok blenny (Salaria pavo), large males with apparent secondary sexual characteristics establish nests and attract the females. Smaller males ("sneakers") try to mimic the female sexual behaviour to approach the nests and fertilize the eggs. These small males later irreversibly become large nesting males. Measurements of aromatase activity in both the gonads and brains suggest that the transition from small males to large ones is associated with increased testicular androgen production accompanied by an increased conversion of androgens into estrogens in the brain [28].

\section{4- A role for aromatase and estradiol in neurogenesis?}

Compared to mammals or birds, the brain of teleost fish exhibits both a strong expression of cyp19a1b in radial glial cells and a high proliferative activity that sustains the

constant growth of their brains $[136 ; 137 ; 138 ; 139 ; 140 ; 141 ; 142]$. In this section, the possible links between these two characteristics are highlighted.

5.4.1 High proliferative activity and aromatase-expressing radial glial cells progenitors in the adult brain of zebrafish 
Adult neurogenesis in the mammalian brain is restricted to the subependymal zone of the lateral ventricle and the subgranular zone of the dentate gyrus of the hippocampus [143; $144 ; 145 ; 146 ; 147 ; 148]$. Similarly, in birds and reptiles, adult neurogenesis is restricted to periventricular zones of the lateral ventricular walls [149; 150; 151]. Interestingly, it is in the brain of teleost fish that adult proliferation is most widespread, as first shown in the guppy, Lebistes reticulates, by autoradiographic studies using tritiated thymidine $[137 ; 138 ; 152]$. Using ${ }^{3} \mathrm{H}$-thymidine injection, and PCNA (Proliferating Cell Nuclear Antigen) or BrdU (5bromo-2-deoxyuridine) immunohistochemistry, it was demonstrated in the stickleback that proliferative zones are associated with the boundaries between brain territories, but are also found in many ventricular regions [139]. This proliferative activity is more important in the anterior brain regions namely in the telencephalon, the diencephalon and the mesencephalon. In zebrafish, proliferation zones are similarly distributed along the ventricles in the anterior brain, but also within the parenchyma in the cerebellum $[64 ; 140 ; 153 ; 154 ; 155]$.

Very recent studies in zebrafish have now established that proliferation results in the generation of new neurons, raising the question of the nature of the progenitors $[64 ; 140 ; 153$; 156]. Using different markers of radial glial cells (Aromatase B, BLBP, GFAP, S-100, nestin) combined to either PCNA or BrdU immunohistochemistry, it was shown that, in many proliferative areas, most of the proliferative cells correspond to radial glial cells $[64 ; 153$; 157], a high percentage of which correspond to aromatase B positive cells. Figure 10 shows an example of proliferating aromatase B-positive radial glial cells labeled by PCNA. Thus, aromatase B-positive radial glial cells have the capacity to divide and long-term experiments using BrdU showed that newborn cells migrate along the radial processes $[64 ; 153 ; 154]$ in a way similar to that described in the mouse cortex during embryogenesis $[158 ; 159]$. Interestingly, newborn cells originating mainly from ventricular precursors migrate within the parenchyma to colonize different brain regions and to differentiate into neurons as shown by 
the use of markers such as HuC/D or acetylated tubulin $[64 ; 153 ; 154 ; 160]$. However, there is increasing evidence for the presence of different subtypes of progenitor cells in the adult zebrafish telencephalon. Fast proliferating cells are localized in the ventral subpallium and posterior pallium. Such cells exhibit weak aromatase B activity [81], whereas slow proliferating cells, corresponding to radial glial cells, are found in the other ventricular telencephalic and diencephalic regions $[153 ; 154]$.

\subsection{2 - Aromatase and estrogens in neurogenesis and brain repair}

Given that radial progenitor cells in fish synthesize estrogens and considering the welldocumented actions of estrogens on cell fate, one may suggest that estrogens could somehow be implicated in modulating the neurogenic activity. Estrogen and aromatase are not only known for having neuroprotective and anti-apoptotic properties $[5 ; 10 ; 161]$ :, a series of recent data suggests that estrogens could also promote neurogenesis or enhance proliferation following brain injury. Despite preliminary data indicating that aromatase inhibitors modulate progenitors proliferation (N. Diotel, unpublished results), the role of estrogens in the brain of adult fish is still poorly documented. In contrast, a growing number of arguments are available in other vertebrates. It is well known that estrogens and/or aromatase act on different aspects of neurogenesis in the brain such as proliferation $[162 ; 163 ; 164 ; 165]$, differentiation $[166 ; 167]$ and migration [168]. In addition, the role of estrogens in neuroprotection is now well established $[161 ; 169 ; 170 ; 171 ; 172]$. In rodents, brain aromatase activity is maximal during embryogenesis and during the perinatal period, when neurogenesis is at a maximum [13]. Interestingly, Martinez-Cerdeño and colleagues recently reported that aromatase is expressed in radial glial cells in the developing mouse cortex, that these cells proliferate and that blocking aromatase activity decreased this proliferative activity [76]. In adults, several studies point to a role of estrogens in regulating proliferation in the dentate gyrus of the hippocampal formation $[162 ; 173 ; 174 ; 175 ; 176]$. Another line of evidence comes from 
studies showing that estrogen production is often associated with brain repair. This is supported first by the fact that after chemical or mechanical lesions, aromatase is de novo expressed in reactive astrocytes in rats [177] and birds [178] or in radial cells in birds [77]. In the zebra finch, mechanical injury of the cortex leads to aromatase expression in radial glial cells facing the lesion and this expression is strongly correlated with increased proliferation near the lesion [77]. Further studies showed that estrogens are directly involved in the brain response to injury and may be acting to provide a rich environment for the production and perhaps protection of new cellc [179].

Mice knocked-out for estrogen receptors alpha and beta (ER $\alpha$ or ER $\beta)$ are useful models to understand the role of estrogens and estrogen receptors in neurogenesis. In contrast to the wild type, estradiol failed to promote neurogenesis in ER $\alpha$ or ER $\beta$ knocked-out mice following experimental ischemic stroke [180]. In addition, ER $\alpha \mathrm{KO}$ mice do not present a sexual dimorphism in the anteroventral periventricular nucleus suggesting that estrogens and their receptors are important for brain differentiation and act on the process of neurogenesis [181]. Moreover, in ER $\beta K O$, a general decrease in neuron number has been observed in several parts of the brain, notably in the somatosensory cortex, whereas the number of astroglial cells in the limbic system is higher than in wild-type mice [165]. Neurons of ER $\beta K O$ mice are also more sensitive to aging, showing the role of estrogens and more precisely the role of the ER $\beta$ pathway in proliferation and neural survival notably with age [165]. Consequently, it seems that ER $\alpha$ is implicated in brain sexual differentiation during development [181], whereas ER $\beta$ would be involved in proliferation and neural survival, notably with age [165].

Aromatase knocked-out (ArKO) mice exhibit a spontaneous apoptosis of pyramidal neurons in the frontal cortex of 12 week old female compared to wild-type animals [182], suggesting that local estrogen synthesis in the brain is necessary for cell survival. Moreover, 
ArKO mice are known to be more sensitive to brain ischemic damage than wild type mice [183], and a number of studies suggest that loss of aromatase could be a risk factor for neurodegenerative diseases such as Parkinson's or Alzheimer's disease $[184 ; 185 ; 186]$.

Interestingly, fish are well known for the high capability of their brains to regenerate after injury [140; 187]. For example, zebrafish are able to regenerate parts of their central nervous system (optical nerve, spinal cord, cerebellum) after different sorts of lesions (optic nerve lesion, spinal cord transection, photo-lesion, stab or chemical lesions) [188]. After mechanical injury of the cerebellum or spinal cord of gymnotiform fish Apteronotus leptorhynchus, neuronal death by apoptosis and replacement of these neurons by new young cells are observed $[140 ; 156 ; 189]$. In order to investigate these mechanisms in the zebrafish brain, preliminary studies using mechanical injury of the telencephalon were performed. After eight days, we observed a $250 \%$ increase in the number of PCNA-immunoreactive cells in the lesioned telencephalic hemisphere, compared to the contralateral one. Aromatase B immunohistochemistry indicates that dividing cells in the lesioned area are either AroBpositive-RGC or, similar to reports in birds [179], cells tightly inserted between aromatse Bradial glial cells (Figure 11). Interestingly, extensions of radial glial cells appear to converge towards the lesion suggesting a scaffolding role for potential newborn cell migration. These results further document the high capacity of proliferation after lesion. In addition, given the role of estrogens and aromatase in neuroprotection and repair, these results strongly suggest that in zebrafish, aromatase is also up-regulated after injury and is implicated in the increase of proliferative activity and brain repair. Such results appear highly similar to those reported in birds following mechanical lesions [77]. This similarity between the proliferative activity in bird and zebrafish following a lesion also suggests that the mechanisms regulating aromatase expression in radial glial cells after injury could be conserved between fish and birds. 


\section{6- Biosynthesis of neurosteroids in the brain of zebrafish}

It is now clear that the fish brain is a major site of aromatase expression and activity [18]. However, the question remains open as to the origin of aromatizable androgens used as substrates for brain aromatization. These C19 androgens can originate from the general circulation, as assumed until now, or alternatively be produced de novo in the brain.

In mammals, the hypothesis that neurosteroids can be produced entirely within the brain was first raised and documented for pregnenolone and dehydroepiandrosterone (DHEA) following studies showing that castration and adrenalectomy did not modify the levels of certain steroid hormones in the brain $[190 ; 191]$. More recently, it was shown that some structures, namely the hippocampus, are able to synthesize estradiol from pregnenolone indicating that other steroidogenic enzymes are expressed in some brain regions $[17 ; 192]$. Similarly, in birds, recent data reported expression of the whole series of steroidogenic enzymes along the brain ventricles during brain development $[6 ; 17]$.

In fish, apart from aromatase, there is only limited information on the expression of other steroidogenic enzymes (cypl1al, $3 \beta$-hsd, P450cypl7 and $17 \beta$-hsd) and their activity in the brain is not well documented.

\section{1- Cytochrome P450 side-chain cleavage (P450scc)}

The first enzymatic step permitting steroid synthesis is the conversion of the precursor cholesterol into the $\mathrm{C}_{21}$-steroid, pregnenolone $\left(\Delta^{5} \mathrm{P}\right)$. This reaction is catalyzed by the cytochrome P450scc, a mitochondrial enzyme encoded by the Cypllal gene [193]. First evidence of P450scc expression in the brain was shown in the rat [194] and these authors demonstrated that the P450scc gene was expressed in glial cells, as well as in neurons of the hippocampus of neonatal and adult rats [17; 195]. In zebrafish, at 14hpf, cypl 1al messengers are detected by in situ hybridization in the yolk syncytial layer, and in adults, cypllal 
mRNAs are detected in the gonads, the interrenal glands and the brain. In addition, RT-PCR transcripts are expressed in the adult brain of zebrafish and, using whole mount in situ hybridization, cypllal gene expression was detected from the telencephalon, preglomerular area, and hypothalamus [196; 197]. However, the precise location of transcripts and their relative abundance in the adult zebrafish brain remain to be determined.

\section{2- P450 17alpha-hydroxylase/c17-20 lyase: P450c17}

The cytochrome P450 17alpha-hydroxylase/c17-20 lyase (P450c17) is a microsomal enzyme that exhibits two different activites: hydroxylase and lyase activities. The first evidence of P450c17 expression in the fish brain was found in fathead (Pimephales promelas) minnow following RT-PCR and southern hybridization, demonstrating P450c17 expression in the brain of males and females [198]. Studies on the black porgy (Acanthopagrus schlegeli) demonstrated that transcripts of key steroidogenic enzymes, namely P450c17, are all expressed in the brain at 60,120 and 150 days post hatching, strongly suggesting that the brain of this fish has the capacity for de novo steroidogenesis [123]. However, the precise localization of expression sites of steroidogenic enzymes in the adult brain requires further research.

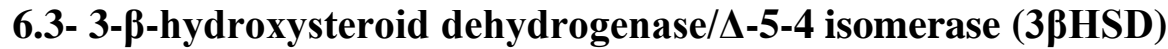

$3 \beta$-HSD is a key steroidogenic enzyme catalyzing the synthesis of progesterone from pregnenolone, 17-hydroxyprogesterone from 17-hydroxypregnenolone, and androstenedione from dehydro-epiandrosterone (DHEA), by oxidation and isomerization reactions. In zebrafish, 3 $\beta$-HSD-like immunoreactivity was shown in several brain regions such as in dorsal telencephalic areas, the central posterior thalamic nucleus, preoptic nuclei or the posterior tuberal nucleus, in neuron-like cells [199]. Additionally, high performance liquid chromatography showed that the brain of adult zebrafish is able to convert pregnenolone into progesterone, suggesting the enzymatic activity of 3ß-HSD [199]. 


\section{4- 17ß-hydroxysteroid dehydrogenase: 17ßHSD}

$17 \beta$-hydroxysteroid dehydrogenases (17ßHSD) are a group of key enzymes known for their importance in the last steps of steroid biosynthesis [200; 201]. These enzymes convert estrone into estradiol (and vice-versa), and it is considered that 17beta-HSD type 3 is the main enzyme catalyzing the reduction of androstenedione into testosterone in mammalian and non mammalian vertebrates. Fish have up to nine types of $17 \beta$ HSD and only four (17ßHSD type $1,2,3$ and 12) have been characterized with respect to their catalytic activity and expression pattern $[202 ; 203 ; 204 ; 205 ; 206]$. In zebrafish, 17ßHSD are expressed in the testis and the ovarian follicles [204; 207] but RT-PCR experiments demonstrate that 17ßHSD type 1, 2 and 3 are also expressed in the brain of both male and female zebrafish [202; 204]. However, another study reported loss of 17ßHSD type 2 enzymatic activity in the zebrafish [203].

\section{5- 5 $\alpha$-reductase}

The microsomal enzyme 5 $\alpha$-reductase reduces the C4-C5 double bond of several steroid substrates $[17 ; 208]$. This enzyme notably catalyzes the conversion of testosterone into the more potent 5 $5 \alpha$-dihydrotestosterone (or also that of progesterone into $5 \alpha$ dihydroprogesterone and 11-deoxycorticosterone into 5 $\alpha$-dihydrodeoxycorticosterone) [17]. Interestingly, early studies showed that the brain of teleost fish exhibits a high $5 \alpha$-reductase activity [19; 209]. Subsequent studies confirmed this high activity in goldfish and toadfish. More recently, 5a-reductase immunoreactivity has been reported in the African lungfish (Protopterus annectens) [210], but there is no information about the cellular localization of $5 \alpha$-reductase in teleosts.

\section{Conclusion and perspectives}

Altogether, these data point to unique features of the fish brain with respect to brain aromatase. However, while some answers have been given, there are still many open questions. The high aromatase activity observed in mature fish is clearly due to up-regulation 
of the cyp19alb gene in the radial glial cells by estrogens and androgens. However, the functions of aromatase expression in these cells are largely open to speculation. The fact that these cells are progenitors in adult fish suggests potential new roles for estrogens in neurogenesis that do not exclude their involvement in "classical" mechanisms. There is increasing evidence for a role of aromatase in the sexualization of the brain and aromatase is clearly involved in sexual behaviour. These new potential functions must also be considered in light of emerging data showing that the teleost brain de novo produces substrates for the aromatase enzyme. Obviously, the functional significance of brain aromatization changes radically if the brain does not need the gonad to produce aromatizable androgens. Recent metabolism studies on the zebrafish brain indicated that key steroidogenic enzymes are active leading to the formation of aromatizable androgens (N. Diotel and J.L Do Rego. unpublished data). In addition, in situ hybridization data established their expression pattern in the vicinity of brain aromatase-expressing cells (N. Diotel et al., unpublished data). These results reinforce the view that the brain of fish is a true steroidogenic organ able to produce estradiol in radial glial progenitors in the absence of gonadal androgens. Given the effects of estrogens on proliferation, differentiation and apoptosis, one may assume that this property contributes to provide the brain with a high neurogenic activity and exceptional plasticity. The persistence of radial glial progenitors in many regions and throughout life makes it likely that neurogenesis can occur in the entire brain throughout adulthood.

In addition to the intrinsic neurogenic properties highlighted above, the brain of adult fish exhibits a situation where there is a coexistence of adult neurogenesis similar to that described in other models, such as the presence of a rostral migratory stream [153], and mechanisms resembling embryonic neurogenesis such as the persistence of radial glial cells allowing brain growth. Figure 12 summarizes this peculiar neurogenic system in teleost fish compared to rodents and the potential involvement of aromatase and estrogen synthesis in 
these processes. Obviously, given the high sensitivity of aromatase expression to estrogens and androgens, gonadal activity is likely to further modulate the neurogenic activity and plasticity in regions such as the preoptic area and the mediobasal hypothalamus, where aromatase expression is highest. It is possible that these characteristics allow the fish brain to construct sex specific circuits throughout life. However, in birds and mice, it has been demonstrated that aromatase activity can be rapidly modulated by post-translation mechanisms, such as phosphorylation $[130 ; 135]$. Such fast changes can also possibly explain the rapid switch between male and female sexual behaviour in simultaneous hermaphrodites.

The precise mechanisms underlying such potential effects remain to be determined. In particular, the role of estrogen receptors $(\mathrm{ER} \alpha, \mathrm{ER} \beta 1$ and $\mathrm{ER} \beta 2)$ in fish neurogenesis is yet poorly documented [18]. So are the potential roles of GPR30 or other membrane-mediated effects. Recently described in the CNS of mammals, GPR30 represents an additional pathway through which estrogen may mediate its effects on different brains functions $[211 ; 212]$. Although GPR30 expression was reported in oocytes and gonads in fish $[213 ; 214 ; 215]$, its expression and functions in the brain remain to be determined [216].

In order to better understand the general and global involvement of aromatase/estrogens in neurogenesis, fish, and notably small fish such as zebrafish and medaka, are powerful models allowing multiple experimental approaches: in vivo imaging, loss and gain of functions by morpholinos and/or RNA interference and probably in a few years by knock-out [217]. Considering the emerging functions of estrogens in the developing brain and the sensitivity of brain aromatase to estrogens and aromatizable androgens, fish are also outstanding models to study the effects of endocrine disruptors on brain development by using the high sensitivity of the cyp19alb gene to estrogenic compounds $[62 ; 66 ; 92 ; 107$; 218]. Indeed, it is now recognized that embryonic stages are highly vulnerable to endocrine disruptors that may cause alterations in brain development and its subsequent functioning or 
disrupt sexual behaviour. In this respect, there is a lack of appropriate and readily accessible mammalian models. In any case, it is very likely that much is to be learnt from fish models with regards to the diverse and complex functions of estrogens in the central nervous system. 
Acknowledgements: Original research mentioned in this review was supported by grants from the National Center of Scientific Research, the French Ministry of Research and Education, the European Union (EDEN and PUBERTIMING Project) and the Agence National de la Recherche (Project NEED: CES 2008-011). Thanks are due to Dr. Marie-Lise Thieulant for critical reading of the manuscript and to Miranda Maybank for improving the English style. 
Table 1: Distribution of aromatase B-immunoreactivity in the brain of teleosts. The number of crosses represents the relative amount of immunoreactivity in the different structures of the same species. N.D.: not documented

$\begin{array}{cc}\begin{array}{c}\text { Plainfin midshipman } \\ \text { Porichthys } \\ \text { notatus }\end{array} & \begin{array}{c}\text { Rainbow trout } \\ \text { Oncorhynchus } \\ \text { mykiss }\end{array} \\ {[7 ; 56]} & {[60]}\end{array}$

Olfactory Bulbs
Subpallium
Pallium
Preoptic area
Hypothalamus
Posterior Recess
Lateral Recess
Optic tectum
Torus
semicircularis
Sonic motor
nucleus
Medulla
oblongata

$+++$

$+$

\section{Zebrafish \\ Danio rerio}

$[18 ; 62 ; 64 ; 65$;
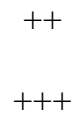

$++(+)$

$++++$

$++++$

$++$

$+(+)$

$+$

$++$

Pejerrey

Odontesthes bonariensis

[67; 115]

(++)/N.D.

(++)/N.D.

$++$

N. D

N.D

$+$
$++$

$++++$

$++++$

N.D

N.D

$+$

Bluehead wrasse

Thalassoma

bifasciatum

[68]

N.D.

$++$

$++$

$++$

$++$

N.D

$++$

$++$

$++$

N.D.

N.D.

N.D. 


\section{References}

[1] C.H. Phoenix, R.W. Goy, A.A. Gerall, and W.C. Young, Organizing action of prenatally administered testosterone propionate on the tissues mediating mating behavior in the female guinea pig. Endocrinology 65 (1959) 369-82.

[2] N.J. MacLusky, and F. Naftolin, Sexual differentiation of the central nervous system. Science 211 (1981) 1294-302.

[3] C.J. Saldanha, K.A. Duncan, and B.J. Walters, Neuroprotective actions of brain aromatase. Front Neuroendocrinol 30 (2009) 106-18.

[4] J. Balthazart, M. Taziaux, K. Holloway, G.F. Ball, and C.A. Cornil, Behavioral effects of brain-derived estrogens in birds. Ann N Y Acad Sci 1163 (2009) 31-48.

[5] L.M. Garcia-Segura, Aromatase in the brain: not just for reproduction anymore. J Neuroendocrinol 20 (2008) 705-12.

[6] B.A. Schlinger, and S.E. London, Neurosteroids and the songbird model system. J Exp Zoolog A Comp Exp Biol 305 (2006) 743-8.

[7] P.M. Forlano, B.A. Schlinger, and A.H. Bass, Brain aromatase: new lessons from nonmammalian model systems. Front Neuroendocrinol 27 (2006) 247-74.

[8] J. Balthazart, and G.F. Ball, Is brain estradiol a hormone or a neurotransmitter? Trends Neurosci 29 (2006) 241-9.

[9] D. Garcia-Ovejero, I. Azcoitia, L.L. Doncarlos, R.C. Melcangi, and L.M. Garcia-Segura, Glia-neuron crosstalk in the neuroprotective mechanisms of sex steroid hormones. Brain Res Brain Res Rev 48 (2005) 273-86.

[10] L.M. Garcia-Segura, S. Veiga, A. Sierra, R.C. Melcangi, and I. Azcoitia, Aromatase: a neuroprotective enzyme. Prog Neurobiol 71 (2003) 31-41.

[11] J. Balthazart, M. Baillien, T.D. Charlier, C.A. Cornil, and G.F. Ball, Multiple mechanisms control brain aromatase activity at the genomic and non-genomic level. $\mathrm{J}$ Steroid Biochem Mol Biol 86 (2003) 367-79.

[12] J. Balthazart, and G.F. Ball, New insights into the regulation and function of brain estrogen synthase (aromatase). Trends Neurosci 21 (1998) 243-9.

[13] E.D. Lephart, A review of brain aromatase cytochrome P450. Brain Res Brain Res Rev 22 (1996) 1-26.

[14] B.S. McEwen, E. Gould, M. Orchinik, N.G. Weiland, and C.S. Woolley, Oestrogens and the structural and functional plasticity of neurons: implications for memory, ageing and neurodegenerative processes. Ciba Found Symp 191 (1995) 52-66; discussion 6673.

[15] F. Naftolin, Brain aromatization of androgens. J Reprod Med 39 (1994) 257-61.

[16] E.D. Lephart, T.D. Lund, and T.L. Horvath, Brain androgen and progesterone metabolizing enzymes: biosynthesis, distribution and function. Brain Res Brain Res Rev 37 (2001) 25-37.

[17] J.L. Do Rego, J.Y. Seong, D. Burel, J. Leprince, V. Luu-The, K. Tsutsui, M.C. Tonon, G. Pelletier, and H. Vaudry, Neurosteroid biosynthesis: enzymatic pathways and neuroendocrine regulation by neurotransmitters and neuropeptides. Front Neuroendocrinol 30 (2009) 259-301.

[18] E. Pellegrini, A. Menuet, C. Lethimonier, F. Adrio, M.M. Gueguen, C. Tascon, I. Anglade, F. Pakdel, and O. Kah, Relationships between aromatase and estrogen receptors in the brain of teleost fish. Gen Comp Endocrinol 142 (2005) 60-6.

[19] G.V. Callard, Z. Petro, and K.J. Ryan, Phylogenetic distribution of aromatase and other androgen-converting enzymes in the central nervous system. Endocrinology 103 (1978) 2283-90. 
[20] M. Pasmanik, and G.V. Callard, Aromatase and 5 alpha-reductase in the teleost brain, spinal cord, and pituitary gland. Gen Comp Endocrinol 60 (1985) 244-51.

[21] B. Borg, R.J. Timmers, and J.G. Lambert, Aromatase activity in the brain of the threespined stickleback, Gasterosteus aculeatus. II. Effects of castration in winter. Exp Biol 47 (1987) 69-71.

[22] B. Borg, R.J. Timmers, and J.G. Lambert, Aromatase activity in the brain of the threespined stickleback, Gasterosteus aculeatus. I. Distribution and effects of season and photoperiod. Exp Biol 47 (1987) 63-8.

[23] R.J. Timmers, and J.G. Lambert, Measurement of aromatase activity in the brain of the African catfish, Clarias gariepinus--a comparison of two assay methods. Comp Biochem Physiol B 88 (1987) 453-6.

[24] R.J. Timmers, J.G. Lambert, J. Peute, H.G. Vullings, and P.G. van Oordt, Localization of aromatase in the brain of the male African catfish, Clarias gariepinus (Burchell), by microdissection and biochemical identification. J Comp Neurol 258 (1987) 368-77.

[25] E. Andersson, B. Borg, and J.G. Lambert, Aromatase activity in brain and pituitary of immature and mature Atlantic salmon (Salmo salar L.) parr. Gen Comp Endocrinol 72 (1988) 394-401.

[26] B. Borg, E. Andersson, I. Mayer, and J.G. Lambert, Aromatase activity in the brain of the three-spined stickleback, Gasterosteus aculeatus. III. Effects of castration under different conditions and of replacement with different androgens. Exp Biol 48 (1989) 149-52.

[27] I. Mayer, B. Borg, I. Berglund, and J.G. Lambert, Effects of castration and androgen treatment on aromatase activity in the brain of mature male Atlantic salmon (Salmo salar L.) parr. Gen Comp Endocrinol 82 (1991) 86-92.

[28] D. Goncalves, M. Teles, J. Alpedrinha, and R.F. Oliveira, Brain and gonadal aromatase activity and steroid hormone levels in female and polymorphic males of the peacock blenny Salaria pavo. Horm Behav 54 (2008) 717-25.

[29] A. Gonzalez, and F. Piferrer, Characterization of aromatase activity in the sea bass: effects of temperature and different catalytic properties of brain and ovarian homogenates and microsomes. J Exp Zool 293 (2002) 500-10.

[30] A. Gonzalez, and F. Piferrer, Aromatase activity in the European sea bass (Dicentrarchus labrax L.) brain. Distribution and changes in relation to age, sex, and the annual reproductive cycle. Gen Comp Endocrinol 132 (2003) 223-30.

[31] B.A. Schlinger, C. Greco, and A.H. Bass, Aromatase activity in the hindbrain vocal control region of a teleost fish: divergence among males with alternative reproductive tactics. . P Roy Soc Lond B Bio 266 (1999) 131-136.

[32] M. Pasmanik, and G.V. Callard, Changes in brain aromatase and 5 alpha-reductase activities correlate significantly with seasonal reproductive cycles in goldfish (Carassius auratus). Endocrinology 122 (1988) 1349-56.

[33] A.C. Melo, and J.S. Ramsdell, Sexual dimorphism of brain aromatase activity in medaka: induction of a female phenotype by estradiol. Environ Health Perspect 109 (2001) 257-64.

[34] G.V. Markov, R. Tavares, C. Dauphin-Villemant, B.A. Demeneix, M.E. Baker, and V. Laudet, Independent elaboration of steroid hormone signaling pathways in metazoans. Proc Natl Acad Sci U S A 106 (2009) 11913-8.

[35] M. Shozu, Y. Zhao, S.E. Bulun, and E.R. Simpson, Multiple splicing events involved in regulation of human aromatase expression by a novel promoter, I.6. Endocrinology 139 (1998) 1610-7.

[36] E.R. Simpson, Y. Zhao, V.R. Agarwal, M.D. Michael, S.E. Bulun, M.M. Hinshelwood, S. Graham-Lorence, T. Sun, C.R. Fisher, K. Qin, and C.R. Mendelson, Aromatase 
expression in health and disease. Recent Prog Horm Res 52 (1997) 185-213; discussion 213-4.

[37] L.G. Graddy, A.A. Kowalski, F.A. Simmen, S.L. Davis, W.W. Baumgartner, and R.C. Simmen, Multiple isoforms of porcine aromatase are encoded by three distinct genes. J Steroid Biochem Mol Biol 73 (2000) 49-57.

[38] C.J. Corbin, A.L. Hughes, J.R. Heffelfinger, T. Berger, T.B. Waltzek, J.F. Roser, T.C. Santos, M.A. Miglino, M.F. Oliveira, F.C. Braga, F.V. Meirelles, and A.J. Conley, Evolution of suiform aromatases: ancestral duplication with conservation of tissuespecific expression in the collared peccary (Pecari tayassu). J Mol Evol 65 (2007) 40312.

[39] D. Steinke, S. Hoegg, H. Brinkmann, and A. Meyer, Three rounds $(1 \mathrm{R} / 2 \mathrm{R} / 3 \mathrm{R})$ of genome duplications and the evolution of the glycolytic pathway in vertebrates. BMC Biol 4 (2006) 16.

[40] M. Tanaka, T.M. Telecky, S. Fukada, S. Adachi, S. Chen, and Y. Nagahama, Cloning and sequence analysis of the cDNA encoding P-450 aromatase (P450arom) from a rainbow trout (Oncorhynchus mykiss) ovary; relationship between the amount of P450arom mRNA and the production of oestradiol-17 beta in the ovary. $\mathrm{J}$ Mol Endocrinol 8 (1992) 53-61.

[41] A. Tchoudakova, and G.V. Callard, Identification of multiple CYP19 genes encoding different cytochrome P450 aromatase isozymes in brain and ovary. Endocrinology 139 (1998) 2179-89.

[42] L.D. Valle, A. Ramina, S. Vianello, P. Belvedere, and L. Colombo, Cloning of two mRNA variants of brain aromatase cytochrome P450 in rainbow trout (Oncorhynchus mykiss Walbaum). J Steroid Biochem Mol Biol 82 (2002) 19-32.

[43] E.F. Chiang, Y.L. Yan, Y. Guiguen, J. Postlethwait, and B. Chung, Two Cyp19 (P450 aromatase) genes on duplicated zebrafish chromosomes are expressed in ovary or brain. Mol Biol Evol 18 (2001) 542-50.

[44] M. Kishida, and G.V. Callard, Distinct cytochrome P450 aromatase isoforms in zebrafish (Danio rerio) brain and ovary are differentially programmed and estrogen regulated during early development. Endocrinology 142 (2001) 740-50.

[45] J.Y. Kwon, B.J. McAndrew, and D.J. Penman, Cloning of brain aromatase gene and expression of brain and ovarian aromatase genes during sexual differentiation in genetic male and female Nile tilapia Oreochromis niloticus. Mol Reprod Dev 59 (2001) 359-70.

[46] M. Blazquez, and F. Piferrer, Cloning, sequence analysis, tissue distribution, and sexspecific expression of the neural form of P450 aromatase in juvenile sea bass (Dicentrarchus labrax). Mol Cell Endocrinol 219 (2004) 83-94.

[47] J.Y. Choi, J.G. Park, H.B. Jeong, Y.D. Lee, A. Takemura, and S.J. Kim, Molecular cloning of cytochrome $\mathrm{P} 450$ aromatases in the protogynous wrasse, Halichoeres tenuispinis. Comp Biochem Physiol B Biochem Mol Biol 141 (2005) 49-59.

[48] S.R. Greytak, D. Champlin, and G.V. Callard, Isolation and characterization of two cytochrome P450 aromatase forms in killifish (Fundulus heteroclitus): differential expression in fish from polluted and unpolluted environments. Aquat Toxicol 71 (2005) 371-89.

[49] Y. Zhang, W. Zhang, L. Zhang, T. Zhu, J. Tian, X. Li, and H. Lin, Two distinct cytochrome P450 aromatases in the orange-spotted grouper (Epinephelus coioides): cDNA cloning and differential mRNA expression. J Steroid Biochem Mol Biol 92 (2004) 39-50.

[50] Y. Zhang, W. Zhang, H. Yang, W. Zhou, C. Hu, and L. Zhang, Two cytochrome P450 aromatase genes in the hermaphrodite ricefield eel Monopterus albus: mRNA 
expression during ovarian development and sex change. J Endocrinol 199 (2008) 317 31.

[51] S. Ijiri, Y. Kazeto, P.M. Lokman, S. Adachi, and K. Yamauchi, Characterization of a cDNA encoding P-450 aromatase (CYP19) from Japanese eel ovary and its expression in ovarian follicles during induced ovarian development. Gen Comp Endocrinol 130 (2003) 193-203.

[52] I. Tzchori, G. Degani, A. Hurvitz, and B. Moav, Cloning and developmental expression of the cytochrome P450 aromatase gene (CYP19) in the European eel (Anguilla anguilla). Gen Comp Endocrinol 138 (2004) 271-80.

[53] E.F. Chiang, Y.L. Yan, S.K. Tong, P.H. Hsiao, Y. Guiguen, J. Postlethwait, and B.C. Chung, Characterization of duplicated zebrafish cyp19 genes. J Exp Zool 290 (2001) 709-14.

[54] J. Zhao, P. Mak, A. Tchoudakova, G. Callard, and S. Chen, Different catalytic properties and inhibitor responses of the goldfish brain and ovary aromatase isozymes. Gen Comp Endocrinol 123 (2001) 180-91.

[55] D. Gelinas, and G.V. Callard, Immunolocalization of aromatase- and androgen receptorpositive neurons in the goldfish brain. Gen Comp Endocrinol 106 (1997) 155-68.

[56] P.M. Forlano, D.L. Deitcher, D.A. Myers, and A.H. Bass, Anatomical distribution and cellular basis for high levels of aromatase activity in the brain of teleost fish: aromatase enzyme and mRNA expression identify glia as source. J Neurosci 21 (2001) 8943-55.

[57] W.A. Gregory, J.C. Edmondson, M.E. Hatten, and C.A. Mason, Cytology and neuronglial apposition of migrating cerebellar granule cells in vitro. J Neurosci 8 (1988) 1728-38.

[58] P. Rakic, Neuronal migration and contact guidance in the primate telencephalon. Postgrad Med J 54 Suppl 1 (1978) 25-40.

[59] B. Onteniente, H. Kimura, and T. Maeda, Comparative study of the glial fibrillary acidic protein in vertebrates by PAP immunohistochemistry. J Comp Neurol 215 (1983) 42736.

[60] A. Menuet, I. Anglade, R. Le Guevel, E. Pellegrini, F. Pakdel, and O. Kah, Distribution of aromatase mRNA and protein in the brain and pituitary of female rainbow trout: Comparison with estrogen receptor alpha. J Comp Neurol 462 (2003) 180-93.

[61] K. Mouriec, J.J. Lareyre, S.K. Tong, Y. Le Page, C. Vaillant, E. Pellegrini, F. Pakdel, B.C. Chung, O. Kah, and I. Anglade, Early regulation of brain aromatase (cyp19a1b) by estrogen receptors during zebrafish development. Dev Dyn 238 (2009) 2641-51.

[62] A. Menuet, E. Pellegrini, F. Brion, M.M. Gueguen, I. Anglade, F. Pakdel, and O. Kah, Expression and estrogen-dependent regulation of the zebrafish brain aromatase gene. $\mathrm{J}$ Comp Neurol 485 (2005) 304-20.

[63] K. Mouriec, M.M. Gueguen, C. Manuel, F. Percevault, M.L. Thieulant, F. Pakdel, and O. Kah, Androgens upregulate cyp19a1b (aromatase B) gene expression in the brain of zebrafish (Danio rerio) through estrogen receptors. Biol Reprod 80 (2009) 889-96.

[64] E. Pellegrini, K. Mouriec, I. Anglade, A. Menuet, Y. Le Page, M.M. Gueguen, M.H. Marmignon, F. Brion, F. Pakdel, and O. Kah, Identification of aromatase-positive radial glial cells as progenitor cells in the ventricular layer of the forebrain in zebrafish. J Comp Neurol 501 (2007) 150-67.

[65] R. Goto-Kazeto, K.E. Kight, Y. Zohar, A.R. Place, and J.M. Trant, Localization and expression of aromatase mRNA in adult zebrafish. Gen Comp Endocrinol 139 (2004) 72-84. 
[66] S.K. Tong, K. Mouriec, M.W. Kuo, E. Pellegrini, M.M. Gueguen, F. Brion, O. Kah, and B.C. Chung, A cyp19a1b-gfp (aromatase B) transgenic zebrafish line that expresses GFP in radial glial cells. Genesis 47 (2009) 67-73.

[67] P.H. Strobl-Mazzulla, N.P. Moncaut, G.C. Lopez, L.A. Miranda, A.V. Canario, and G.M. Somoza, Brain aromatase from pejerrey fish (Odontesthes bonariensis): cDNA cloning, tissue expression, and immunohistochemical localization. Gen Comp Endocrinol 143 (2005) 21-32.

[68] K.E. Marsh, L.M. Creutz, M.B. Hawkins, and J. Godwin, Aromatase immunoreactivity in the bluehead wrasse brain, Thalassoma bifasciatum: immunolocalization and coregionalization with arginine vasotocin and tyrosine hydroxylase. Brain Res 1126 (2006) 91-101.

[69] M.V. Wu, D.S. Manoli, E.J. Fraser, J.K. Coats, J. Tollkuhn, S. Honda, N. Harada, and N.M. Shah, Estrogen masculinizes neural pathways and sex-specific behaviors. Cell 139 (2009) 61-72.

[70] C.K. Wagner, and J.I. Morrell, Neuroanatomical distribution of aromatase MRNA in the rat brain: indications of regional regulation. J Steroid Biochem Mol Biol 61 (1997) 307-14.

[71] G.C. Panzica, C. Viglietti-Panzica, and J. Balthazart, The sexually dimorphic medial preoptic nucleus of quail: a key brain area mediating steroid action on male sexual behavior. Front Neuroendocrinol 17 (1996) 51-125.

[72] A. Foidart, A. de Clerck, N. Harada, and J. Balthazart, Aromatase-immunoreactive cells in the quail brain: effects of testosterone and sex dimorphism. Physiol Behav 55 (1994) 453-64.

[73] C.J. Saldanha, M.J. Tuerk, Y.H. Kim, A.O. Fernandes, A.P. Arnold, and B.A. Schlinger, Distribution and regulation of telencephalic aromatase expression in the zebra finch revealed with a specific antibody. J Comp Neurol 423 (2000) 619-30.

[74] J.G. Yague, A. Munoz, P. de Monasterio-Schrader, J. Defelipe, L.M. Garcia-Segura, and I. Azcoitia, Aromatase expression in the human temporal cortex. Neuroscience 138 (2006) 389-401.

[75] J.G. Yague, A.C. Wang, W.G. Janssen, P.R. Hof, L.M. Garcia-Segura, I. Azcoitia, and J.H. Morrison, Aromatase distribution in the monkey temporal neocortex and hippocampus. Brain Res 1209 (2008) 115-27.

[76] V. Martinez-Cerdeno, S.C. Noctor, and A.R. Kriegstein, Estradiol stimulates progenitor cell division in the ventricular and subventricular zones of the embryonic neocortex. Eur J Neurosci 24 (2006) 3475-88.

[77] R.S. Peterson, D.W. Lee, G. Fernando, and B.A. Schlinger, Radial glia express aromatase in the injured zebra finch brain. J Comp Neurol 475 (2004) 261-9.

[78] P.M. Forlano, D.L. Deitcher, and A.H. Bass, Distribution of estrogen receptor alpha mRNA in the brain and inner ear of a vocal fish with comparisons to sites of aromatase expression. J Comp Neurol 483 (2005) 91-113.

[79] M. Bentivoglio, and P. Mazzarello, The history of radial glia. Brain Res Bull 49 (1999) 305-15.

[80] R.S. Cameron, and P. Rakic, Glial cell lineage in the cerebral cortex: a review and synthesis. Glia 4 (1991) 124-37.

[81] M. März, P. Chapouton, N. Diotel, C. Vaillant, B. Hesl, S.L. Chen, O. Kah, L. BallyCuif, and U. Strähle, Heterogeneity in progenitor cell subtypes in the ventricular zone of the zebrafish adult telencephalon. Glia in press.

[82] A. Tchoudakova, M. Kishida, E. Wood, and G.V. Callard, Promoter characteristics of two cyp19 genes differentially expressed in the brain and ovary of teleost fish. J Steroid Biochem Mol Biol 78 (2001) 427-39. 
[83] S.K. Tong, and B.C. Chung, Analysis of zebrafish cyp19 promoters. J Steroid Biochem Mol Biol 86 (2003) 381-6.

[84] G.V. Callard, A.V. Tchoudakova, M. Kishida, and E. Wood, Differential tissue distribution, developmental programming, estrogen regulation and promoter characteristics of cyp19 genes in teleost fish. J Steroid Biochem Mol Biol 79 (2001) 305-14.

[85] G.V. Callard, and A. Tchoudakova, Evolutionary and functional significance of two CYP19 genes differentially expressed in brain and ovary of goldfish. J Steroid Biochem Mol Biol 61 (1997) 387-92.

[86] X. Chang, T. Kobayashi, B. Senthilkumaran, H. Kobayashi-Kajura, C.C. Sudhakumari, and Y. Nagahama, Two types of aromatase with different encoding genes, tissue distribution and developmental expression in Nile tilapia (Oreochromis niloticus). Gen Comp Endocrinol 141 (2005) 101-15.

[87] A.J. Kuhl, S. Manning, and M. Brouwer, Brain aromatase in Japanese medaka (Oryzias latipes): Molecular characterization and role in xenoestrogen-induced sex reversal. J Steroid Biochem Mol Biol 96 (2005) 67-77.

[88] J.N. Nocillado, A. Elizur, A. Avitan, F. Carrick, and B. Levavi-Sivan, Cytochrome P450 aromatase in grey mullet: cDNA and promoter isolation; brain, pituitary and ovarian expression during puberty. Mol Cell Endocrinol 263 (2007) 65-78.

[89] V. Toffolo, P. Belvedere, L. Colombo, and L.D. Valle, Tissue-specific transcriptional initiation of the CYP19 genes in rainbow trout, with analysis of splicing patterns and promoter sequences. Gen Comp Endocrinol 153 (2007) 311-9.

[90] R.J. Handa, T.R. Pak, A.E. Kudwa, T.D. Lund, and L. Hinds, An alternate pathway for androgen regulation of brain function: activation of estrogen receptor beta by the metabolite of dihydrotestosterone, 5alpha-androstane-3beta,17beta-diol. Horm Behav 53 (2008) 741-52.

[91] I. Anglade, F. Pakdel, T. Bailhache, F. Petit, G. Salbert, P. Jego, Y. Valotaire, and O. Kah, Distribution of estrogen receptor-immunoreactive cells in the brain of the rainbow trout (Oncorhynchus mykiss). J Neuroendocrinol 6 (1994) 573-83.

[92] Y. Le Page, A. Menuet, O. Kah, and F. Pakdel, Characterization of a cis-acting element involved in cell-specific expression of the zebrafish brain aromatase gene. Mol Reprod Dev 75 (2008) 1549-57.

[93] V. Krishnan, W. Porter, M. Santostefano, X. Wang, and S. Safe, Molecular mechanism of inhibition of estrogen-induced cathepsin $D$ gene expression by 2,3,7,8tetrachlorodibenzo-p-dioxin (TCDD) in MCF-7 cells. Mol Cell Biol 15 (1995) 6710-9.

[94] T.R. Zacharewski, K.L. Bondy, P. McDonell, and Z.F. Wu, Antiestrogenic effect of 2,3,7,8-tetrachlorodibenzo-p-dioxin on 17 beta-estradiol-induced pS2 expression. Cancer Res 54 (1994) 2707-13.

[95] F. Ohtake, K. Takeyama, T. Matsumoto, H. Kitagawa, Y. Yamamoto, K. Nohara, C. Tohyama, A. Krust, J. Mimura, P. Chambon, J. Yanagisawa, Y. Fujii-Kuriyama, and S. Kato, Modulation of oestrogen receptor signalling by association with the activated dioxin receptor. Nature 423 (2003) 545-50.

[96] R. Metivier, A. Stark, G. Flouriot, M.R. Hubner, H. Brand, G. Penot, D. Manu, S. Denger, G. Reid, M. Kos, R.B. Russell, O. Kah, F. Pakdel, and F. Gannon, A dynamic structural model for estrogen receptor-alpha activation by ligands, emphasizing the role of interactions between distant A and E domains. Mol Cell 10 (2002) 1019-32.

[97] S. Baron, A. Escande, G. Alberola, K. Bystricky, P. Balaguer, and H. Richard-Foy, Estrogen receptor alpha and the activating protein-1 complex cooperate during insulinlike growth factor-I-induced transcriptional activation of the pS2/TFF1 gene. J Biol Chem 282 (2007) 11732-41. 
[98] V. Pezzi, R. Sirianni, A. Chimento, M. Maggiolini, S. Bourguiba, C. Delalande, S. Carreau, S. Ando, E.R. Simpson, and C.D. Clyne, Differential expression of steroidogenic factor-1/adrenal 4 binding protein and liver receptor homolog-1 (LRH1)/fetoprotein transcription factor in the rat testis: LRH-1 as a potential regulator of testicular aromatase expression. Endocrinology 145 (2004) 2186-96.

[99] Y. Ohmuro-Matsuyama, K. Okubo, M. Matsuda, S. Ijiri, D. Wang, G. Guan, T. Suzuki, M. Matsuyama, K. Morohashi, and Y. Nagahama, Liver receptor homologue-1 (LRH1) activates the promoter of brain aromatase (cyp19a2) in a teleost fish, the medaka, Oryzias latipes. Mol Reprod Dev 74 (2007) 1065-71.

[100] E. Fayard, J. Auwerx, and K. Schoonjans, LRH-1: an orphan nuclear receptor involved in development, metabolism and steroidogenesis. Trends Cell Biol 14 (2004) 250-60.

[101] T. Yazawa, Y. Inanoka, T. Mizutani, M. Kuribayashi, A. Umezawa, and K. Miyamoto, Liver receptor homolog-1 regulates the transcription of steroidogenic enzymes and induces the differentiation of mesenchymal stem cells into steroidogenic cells. Endocrinology 150 (2009) 3885-93.

[102] K. Cheshenko, F. Pakdel, H. Segner, O. Kah, and R.I. Eggen, Interference of endocrine disrupting chemicals with aromatase CYP19 expression or activity, and consequences for reproduction of teleost fish. Gen Comp Endocrinol 155 (2008) 31-62.

[103] K. Cheshenko, F. Brion, Y. Le Page, N. Hinfray, F. Pakdel, O. Kah, H. Segner, and R.I. Eggen, Expression of zebra fish aromatase cyp19a and cyp19b genes in response to the ligands of estrogen receptor and aryl hydrocarbon receptor. Toxicol Sci 96 (2007) 255-67.

[104] Y. Le Page, M. Scholze, O. Kah, and F. Pakdel, Assessment of xenoestrogens using three distinct estrogen receptors and the zebrafish brain aromatase gene in a highly responsive glial cell system. Environ Health Perspect 114 (2006) 752-8.

[105] T. King Heiden, R.J. Hutz, and M.J.I. Carvan, Accumulation, tissue distribution, and maternal transfer of dietary 2,3,7,8-tetrachlorodibenzo- $p$-dioxin: impacts on reproductive success of zebrafish. Toxicol. Sci. 87 (2005) 497-507.

[106] T. King Heiden, M.J.I. Carvan, and R.J. Hutz, Inhibition of follicular development, vitellogenesis, and serum 17beta-estradiol concentrations in zebrafish following chronic, sublethal dietary exposure to 2,3,7,8-tetrachlorodibenzo- $p$-dioxin. Toxicol. Sci. 90 (2006) 490-499.

[107] Y. Kazeto, A.R. Place, and J.M. Trant, Effects of endocrine disrupting chemicals on the expression of CYP19 genes in zebrafish (Danio rerio) juveniles. Aquat Toxicol 69 (2004) 25-34.

[108] F. Pelegri, and S. Schulte-Merker, A gynogenesis-based screen for maternal-effect genes in the zebrafish, Danio rerio. Methods Cell Biol 60 (1999) 1-20.

[109] J.M. Trant, S. Gavasso, J. Ackers, B.C. Chung, and A.R. Place, Developmental expression of cytochrome P450 aromatase genes (CYP19a and CYP19b) in zebrafish fry (Danio rerio). J Exp Zool 290 (2001) 475-83.

[110] E. Kallivretaki, R.I. Eggen, S.C. Neuhauss, O. Kah, and H. Segner, The zebrafish, brain-specific, aromatase cyp19a2 is neither expressed nor distributed in a sexually dimorphic manner during sexual differentiation. Dev Dyn 236 (2007) 3155-66.

[111] M. Schartl, A comparative view on sex determination in medaka. Mech Dev 121 (2004) 639-45.

[112] A. Menuet, E. Pellegrini, I. Anglade, O. Blaise, V. Laudet, O. Kah, and F. Pakdel, Molecular characterization of three estrogen receptor forms in zebrafish: binding characteristics, transactivation properties, and tissue distributions. Biol Reprod 66 (2002) 1881-92. 
[113] T.K. Andreassen, K. Skjoedt, I. Anglade, O. Kah, and B. Korsgaard, Molecular cloning, characterisation, and tissue distribution of oestrogen receptor alpha in eelpout (Zoarces viviparus). Gen Comp Endocrinol 132 (2003) 356-68.

[114] M.B. Hawkins, J. Godwin, D. Crews, and P. Thomas, The distributions of the duplicate oestrogen receptors ER-beta a and ER-beta $b$ in the forebrain of the Atlantic croaker (Micropogonias undulatus): evidence for subfunctionalization after gene duplication. Proc Biol Sci 272 (2005) 633-41.

[115] P.H. Strobl-Mazzulla, C. Lethimonier, M.M. Gueguen, M. Karube, J.I. Fernandino, G. Yoshizaki, R. Patino, C.A. Strussmann, O. Kah, and G.M. Somoza, Brain aromatase (Cyp19A2) and estrogen receptors, in larvae and adult pejerrey fish Odontesthes bonariensis: Neuroanatomical and functional relations. Gen Comp Endocrinol 158 (2008) 191-201.

[116] C.D. Toran-Allerand, Minireview: A plethora of estrogen receptors in the brain: where will it end? Endocrinology 145 (2004) 1069-74.

[117] B. McEwen, Estrogen actions throughout the brain. Recent Prog Horm Res 57 (2002) 357-84.

[118] E.J. Filardo, and P. Thomas, GPR30: a seven-transmembrane-spanning estrogen receptor that triggers EGF release. Trends Endocrinol Metab 16 (2005) 362-7.

[119] L.A. Arbogast, Estrogen genomic and membrane actions at an intersection. Trends Endocrinol Metab 19 (2008) 1-2.

[120] N. Vasudevan, and D.W. Pfaff, Non-genomic actions of estrogens and their interaction with genomic actions in the brain. Front Neuroendocrinol 29 (2008) 238-57.

[121] Y. Guiguen, A. Fostier, F. Piferrer, and C.F. Chang, Ovarian aromatase and estrogens: A pivotal role for gonadal sex differentiation and sex change in fish. Gen Comp Endocrinol (2009).

[122] M. Blazquez, A. Gonzalez, M. Papadaki, C. Mylonas, and F. Piferrer, Sex-related changes in estrogen receptors and aromatase gene expression and enzymatic activity during early development and sex differentiation in the European sea bass (Dicentrarchus labrax). Gen Comp Endocrinol 158 (2008) 95-101.

[123] S. Tomy, G.C. Wu, H.R. Huang, S. Dufour, and C.F. Chang, Developmental expression of key steroidogenic enzymes in the brain of protandrous black porgy fish, Acanthopagrus schlegeli. J Neuroendocrinol 19 (2007) 643-55.

[124] P.L. Munday, P.M. Buston, and R.R. Warner, Diversity and flexibility of sex-change strategies in animals. Trends Ecol Evol 21 (2006) 89-95.

[125] A. Munakata, and M. Kobayashi, Endocrine control of sexual behavior in teleost fish. Gen Comp Endocrinol (2009).

[126] M. Kobayashi, P.W. Sorensen, and N.E. Stacey, Hormonal and pheromonalcontrol of spawning behavior in goldfish. . Fish Physiol Biochem 26 (2002) 71-84.

[127] B. Breton, and E. Sambroni, Steroid activation of the brain-pituitary complex gonadotropic function in the triploid rainbow trout Oncorhynchus mykiss. Gen Comp Endocrinol 101 (1996) 155-64.

[128] E.A. Dubois, M.A. Florijn, M.A. Zandbergen, J. Peute, and H.J. Goos, Testosterone accelerates the development of the catfish GnRH system in the brain of immature African catfish (Clarias gariepinus). Gen Comp Endocrinol 112 (1998) 383-93.

[129] J. Balthazart, C.A. Cornil, T.D. Charlier, M. Taziaux, and G.F. Ball, Estradiol, a key endocrine signal in the sexual differentiation and activation of reproductive behavior in quail. J Exp Zool A Ecol Genet Physiol 311 (2009) 323-45.

[130] J. Balthazart, C.A. Cornil, M. Taziaux, T.D. Charlier, M. Baillien, and G.F. Ball, Rapid changes in production and behavioral action of estrogens. Neuroscience 138 (2006) 783-91. 
[131] P.M. Forlano, and A.H. Bass, Seasonal plasticity of brain aromatase mRNA expression in glia: divergence across sex and vocal phenotypes. J Neurobiol 65 (2005) 37-49.

[132] L. Remage-Healey, and A.H. Bass, Plasticity in brain sexuality is revealed by the rapid actions of steroid hormones. J Neurosci 27 (2007) 1114-22.

[133] E.D. Clotfelter, and A.C. Rodriguez, Behavioral changes in fish exposed to phytoestrogens. Environ Pollut 144 (2006) 833-9.

[134] J.R. Colman, D. Baldwin, L.L. Johnson, and N.L. Scholz, Effects of the synthetic estrogen, 17alpha-ethinylestradiol, on aggression and courtship behavior in male zebrafish (Danio rerio). Aquat Toxicol 91 (2009) 346-54.

[135] M.P. Black, J. Balthazart, M. Baillien, and M.S. Grober, Socially induced and rapid increases in aggression are inversely related to brain aromatase activity in a sexchanging fish, Lythrypnus dalli. Proc Biol Sci 272 (2005) 2435-40.

[136] G.K. Zupanc, and I. Horschke, Proliferation zones in the brain of adult gymnotiform fish: a quantitative mapping study. J Comp Neurol 353 (1995) 213-33.

[137] D. Kranz, and W. Richter, [Autoradiographic studies on the synthesis of DNA in the cerebellum and medulla oblongata of teleosts of various ages]. Z Mikrosk Anat Forsch 82 (1970) 264-92.

[138] D. Kranz, and W. Richter, [Autoradiographic studies on the localization of the matrix zones of the diencephalon of young and adult Lebistes reticulatus (Teleostae)]. Z Mikrosk Anat Forsch 82 (1970) 42-66.

[139] P. Ekstrom, C.M. Johnsson, and L.M. Ohlin, Ventricular proliferation zones in the brain of an adult teleost fish and their relation to neuromeres and migration (secondary matrix) zones. J Comp Neurol 436 (2001) 92-110.

[140] G.K. Zupanc, Adult neurogenesis and neuronal regeneration in the central nervous system of teleost fish. Brain Behav Evol 58 (2001) 250-75.

[141] G.K. Zupanc, A comparative approach towards the understanding of adult neurogenesis. Brain Behav Evol 58 (2001) 246-9.

[142] G.K. Zupanc, and M.M. Zupanc, Birth and migration of neurons in the central posterior/prepacemaker nucleus during adulthood in weakly electric knifefish (Eigenmannia sp.). Proc Natl Acad Sci U S A 89 (1992) 9539-43.

[143] A. Alvarez-Buylla, and J.M. Garcia-Verdugo, Neurogenesis in adult subventricular zone. J Neurosci 22 (2002) 629-34.

[144] F. Doetsch, and R. Hen, Young and excitable: the function of new neurons in the adult mammalian brain. Curr Opin Neurobiol 15 (2005) 121-8.

[145] P.M. Lledo, and A. Saghatelyan, Integrating new neurons into the adult olfactory bulb: joining the network, life-death decisions, and the effects of sensory experience. Trends Neurosci 28 (2005) 248-54.

[146] P. Taupin, and F.H. Gage, Adult neurogenesis and neural stem cells of the central nervous system in mammals. J Neurosci Res 69 (2002) 745-9.

[147] G. Kempermann, Neuronal stem cells and adult neurogenesis. Ernst Schering Res Found Workshop (2002) 17-28.

[148] A.D. Garcia, N.B. Doan, T. Imura, T.G. Bush, and M.V. Sofroniew, GFAP-expressing progenitors are the principal source of constitutive neurogenesis in adult mouse forebrain. Nat Neurosci 7 (2004) 1233-41.

[149] B.W. Lindsey, and V. Tropepe, A comparative framework for understanding the biological principles of adult neurogenesis. Prog Neurobiol 80 (2006) 281-307.

[150] J.M. Garcia-Verdugo, S. Ferron, N. Flames, L. Collado, E. Desfilis, and E. Font, The proliferative ventricular zone in adult vertebrates: a comparative study using reptiles, birds, and mammals. Brain Res Bull 57 (2002) 765-75. 
[151] S.A. Goldman, Adult neurogenesis: from canaries to the clinic. J Neurobiol 36 (1998) 267-86.

[152] W. Kirsche, [On postembryonic matrix zones in the brain of various vertebrates and their relationship to the study of the brain structure]. Z Mikrosk Anat Forsch 77 (1967) 313-406.

[153] B. Adolf, P. Chapouton, C.S. Lam, S. Topp, B. Tannhauser, U. Strahle, M. Gotz, and L. Bally-Cuif, Conserved and acquired features of adult neurogenesis in the zebrafish telencephalon. Dev Biol 295 (2006) 278-93.

[154] H. Grandel, J. Kaslin, J. Ganz, I. Wenzel, and M. Brand, Neural stem cells and neurogenesis in the adult zebrafish brain: origin, proliferation dynamics, migration and cell fate. Dev Biol 295 (2006) 263-77.

[155] P. Chapouton, R. Jagasia, and L. Bally-Cuif, Adult neurogenesis in non-mammalian vertebrates. Bioessays 29 (2007) 745-57.

[156] G.K. Zupanc, and M.M. Zupanc, New neurons for the injured brain: mechanisms of neuronal regeneration in adult teleost fish. Regen Med 1 (2006) 207-16.

[157] C.S. Lam, M. Marz, and U. Strahle, gfap and nestin reporter lines reveal characteristics of neural progenitors in the adult zebrafish brain. Dev Dyn 238 (2009) 475-86.

[158] S.C. Noctor, A.C. Flint, T.A. Weissman, R.S. Dammerman, and A.R. Kriegstein, Neurons derived from radial glial cells establish radial units in neocortex. Nature 409 (2001) 714-20.

[159] S.C. Noctor, A.C. Flint, T.A. Weissman, W.S. Wong, B.K. Clinton, and A.R. Kriegstein, Dividing precursor cells of the embryonic cortical ventricular zone have morphological and molecular characteristics of radial glia. J Neurosci 22 (2002) 316173.

[160] G.K. Zupanc, Neurogenesis and neuronal regeneration in the adult fish brain

. J Comp Physiol A Neuroethol Sens Neural Behav Physiol 192 (2006) 649-70.

[161] C. Behl, Oestrogen as a neuroprotective hormone. Nat Rev Neurosci 3 (2002) 433-42.

[162] B.K. Ormerod, T.T. Lee, and L.A. Galea, Estradiol enhances neurogenesis in the dentate gyri of adult male meadow voles by increasing the survival of young granule neurons. Neuroscience 128 (2004) 645-54.

[163] C.A. Mazzucco, S.E. Lieblich, B.I. Bingham, M.A. Williamson, V. Viau, and L.A. Galea, Both estrogen receptor alpha and estrogen receptor beta agonists enhance cell proliferation in the dentate gyrus of adult female rats. Neuroscience 141 (2006) 1793800.

[164] D.N. Abrous, M. Koehl, and M. Le Moal, Adult neurogenesis: from precursors to network and physiology. Physiol Rev 85 (2005) 523-69.

[165] L. Wang, S. Andersson, M. Warner, and J.A. Gustafsson, Morphological abnormalities in the brains of estrogen receptor beta knockout mice. Proc Natl Acad Sci U S A 98 (2001) 2792-6.

[166] G. Murakami, T. Tsurugizawa, Y. Hatanaka, Y. Komatsuzaki, N. Tanabe, H. Mukai, Y. Hojo, S. Kominami, T. Yamazaki, T. Kimoto, and S. Kawato, Comparison between basal and apical dendritic spines in estrogen-induced rapid spinogenesis of CA1 principal neurons in the adult hippocampus. Biochem Biophys Res Commun 351 (2006) 553-8.

[167] A.K. Murashov, E.S. Pak, W.A. Hendricks, and L.M. Tatko, 17beta-Estradiol enhances neuronal differentiation of mouse embryonic stem cells. FEBS Lett 569 (2004) 165-8.

[168] X. Fan, M. Warner, and J.A. Gustafsson, Estrogen receptor beta expression in the embryonic brain regulates development of calretinin-immunoreactive GABAergic interneurons. Proc Natl Acad Sci U S A 103 (2006) 19338-43. 
[169] N.J. Alkayed, S. Goto, N. Sugo, H.D. Joh, J. Klaus, B.J. Crain, O. Bernard, R.J. Traystman, and P.D. Hurn, Estrogen and Bcl-2: gene induction and effect of transgene in experimental stroke. J Neurosci 21 (2001) 7543-50.

[170] Y. Merot, F. Ferriere, E. Debroas, G. Flouriot, D. Duval, and C. Saligaut, Estrogen receptor alpha mediates neuronal differentiation and neuroprotection in PC12 cells: critical role of the A/B domain of the receptor. J Mol Endocrinol 35 (2005) 257-67.

[171] B. Moosmann, and C. Behl, The antioxidant neuroprotective effects of estrogens and phenolic compounds are independent from their estrogenic properties. Proc Natl Acad Sci U S A 96 (1999) 8867-72.

[172] L. Zhou, N. Lehan, U. Wehrenberg, E. Disteldorf, R. von Lossow, U. Mares, H. Jarry, and G.M. Rune, Neuroprotection by estradiol: a role of aromatase against spine synapse loss after blockade of GABA(A) receptors. Exp Neurol 203 (2007) 72-81.

[173] J.L. Pawluski, S. Brummelte, C.K. Barha, T.M. Crozier, and L.A. Galea, Effects of steroid hormones on neurogenesis in the hippocampus of the adult female rodent during the estrous cycle, pregnancy, lactation and aging. Front Neuroendocrinol (2009).

[174] L.A. Galea, T.S. Perrot-Sinal, M. Kavaliers, and K.P. Ossenkopp, Relations of hippocampal volume and dentate gyrus width to gonadal hormone levels in male and female meadow voles. Brain Res 821 (1999) 383-91.

[175] P. Tanapat, N.B. Hastings, and E. Gould, Ovarian steroids influence cell proliferation in the dentate gyrus of the adult female rat in a dose- and time-dependent manner. $\mathrm{J}$ Comp Neurol 481 (2005) 252-65.

[176] L.A. Galea, Gonadal hormone modulation of neurogenesis in the dentate gyrus of adult male and female rodents. Brain Res Rev 57 (2008) 332-41.

[177] L.M. Garcia-Segura, A. Wozniak, I. Azcoitia, J.R. Rodriguez, R.E. Hutchison, and J.B. Hutchison, Aromatase expression by astrocytes after brain injury: implications for local estrogen formation in brain repair. Neuroscience 89 (1999) 567-78.

[178] R.S. Peterson, C.J. Saldanha, and B.A. Schlinger, Rapid upregulation of aromatase mRNA and protein following neural injury in the zebra finch (Taeniopygia guttata). $\mathrm{J}$ Neuroendocrinol 13 (2001) 317-23.

[179] D.W. Lee, G. Fernando, R.S. Peterson, T.A. Allen, and B.A. Schlinger, Estrogen mediation of injury-induced cell birth in neuroproliferative regions of the adult zebra finch brain. Dev Neurobiol 67 (2007) 1107-17.

[180] S. Suzuki, L.M. Gerhold, M. Bottner, S.W. Rau, C. Dela Cruz, E. Yang, H. Zhu, J. Yu, A.B. Cashion, M.S. Kindy, I. Merchenthaler, F.H. Gage, and P.M. Wise, Estradiol enhances neurogenesis following ischemic stroke through estrogen receptors alpha and beta. J Comp Neurol 500 (2007) 1064-75.

[181] R.B. Simerly, M.C. Zee, J.W. Pendleton, D.B. Lubahn, and K.S. Korach, Estrogen receptor-dependent sexual differentiation of dopaminergic neurons in the preoptic region of the mouse. Proc Natl Acad Sci U S A 94 (1997) 14077-82.

[182] R.A. Hill, H.K. Chua, M.E. Jones, E.R. Simpson, and W.C. Boon, Estrogen deficiency results in apoptosis in the frontal cortex of adult female aromatase knockout mice. Mol Cell Neurosci 41 (2009) 1-7.

[183] L.D. McCullough, K. Blizzard, E.R. Simpson, O.K. Oz, and P.D. Hurn, Aromatase cytochrome $\mathrm{P} 450$ and extragonadal estrogen play a role in ischemic neuroprotection. $\mathrm{J}$ Neurosci 23 (2003) 8701-5.

[184] M.C. Morale, F. L'Episcopo, C. Tirolo, G. Giaquinta, S. Caniglia, N. Testa, P. Arcieri, P.A. Serra, G. Lupo, M. Alberghina, N. Harada, S. Honda, G.C. Panzica, and B. Marchetti, Loss of aromatase cytochrome P450 function as a risk factor for Parkinson's disease? Brain Res Rev 57 (2008) 431-43. 
[185] O. Combarros, P. Sanchez-Juan, J.A. Riancho, I. Mateo, E. Rodriguez-Rodriguez, J. Infante, I. Garcia-Gorostiaga, J.L. Vazquez-Higuera, and J. Berciano, Aromatase and interleukin-10 genetic variants interactively modulate Alzheimer's disease risk. J Neural Transm 115 (2008) 863-7.

[186] M. Hiltunen, S. Iivonen, and H. Soininen, Aromatase enzyme and Alzheimer's disease. Minerva Endocrinol 31 (2006) 61-73.

[187] G.K. Zupanc, Towards brain repair: Insights from teleost fish. Semin Cell Dev Biol (2008).

[188] C.G. Becker, and T. Becker, Adult zebrafish as a model for successful central nervous system regeneration. Restor Neurol Neurosci 26 (2008) 71-80.

[189] G.K. Zupanc, Neurogenesis, cell death and regeneration in the adult gymnotiform brain. J Exp Biol 202 (1999) 1435-46.

[190] E.E. Baulieu, Neurosteroids: of the nervous system, by the nervous system, for the nervous system. Recent Prog Horm Res 52 (1997) 1-32.

[191] C. Corpechot, P. Robel, M. Axelson, J. Sjovall, and E.E. Baulieu, Characterization and measurement of dehydroepiandrosterone sulfate in rat brain. Proc Natl Acad Sci U S A 78 (1981) 4704-7.

[192] Y. Hojo, T.A. Hattori, T. Enami, A. Furukawa, K. Suzuki, H.T. Ishii, H. Mukai, J.H. Morrison, W.G. Janssen, S. Kominami, N. Harada, T. Kimoto, and S. Kawato, Adult male rat hippocampus synthesizes estradiol from pregnenolone by cytochromes P45017alpha and P450 aromatase localized in neurons. Proc Natl Acad Sci U S A 101 (2004) 865-70.

[193] S. Lieberman, N.J. Greenfield, and A. Wolfson, A heuristic proposal for understanding steroidogenic processes. Endocr Rev 5 (1984) 128-48.

[194] C. Le Goascogne, P. Robel, M. Gouezou, N. Sananes, E.E. Baulieu, and M. Waterman, Neurosteroids: cytochrome P-450scc in rat brain. Science 237 (1987) 1212-5.

[195] T. Kimoto, T. Tsurugizawa, Y. Ohta, J. Makino, H. Tamura, Y. Hojo, N. Takata, and S. Kawato, Neurosteroid synthesis by cytochrome p450-containing systems localized in the rat brain hippocampal neurons: N-methyl-D-aspartate and calcium-dependent synthesis. Endocrinology 142 (2001) 3578-89.

[196] H.J. Hsu, P. Hsiao, M.W. Kuo, and B.C. Chung, Expression of zebrafish cyp11a1 as a maternal transcript and in yolk syncytial layer. Gene Expr Patterns 2 (2002) 219-22.

[197] M.C. Hu, H.J. Hsu, I.C. Guo, and B.C. Chung, Function of Cyp11a1 in animal models. Mol Cell Endocrinol 215 (2004) 95-100.

[198] S. Halm, J.Y. Kwon, M. Rand-Weaver, J.P. Sumpter, N. Pounds, T.H. Hutchinson, and C.R. Tyler, Cloning and gene expression of P450 17alpha-hydroxylase,17,20-lyase cDNA in the gonads and brain of the fathead minnow Pimephales promelas. Gen Comp Endocrinol 130 (2003) 256-66.

[199] H. Sakamoto, K. Ukena, and K. Tsutsui, Activity and localization of 3betahydroxysteroid dehydrogenase/ Delta5-Delta4-isomerase in the zebrafish central nervous system. J Comp Neurol 439 (2001) 291-305.

[200] H. Peltoketo, V. Luu-The, J. Simard, and J. Adamski, 17beta-hydroxysteroid dehydrogenase (HSD)/17-ketosteroid reductase (KSR) family; nomenclature and main characteristics of the 17HSD/KSR enzymes. J Mol Endocrinol 23 (1999) 1-11.

[201] J. Adamski, and F.J. Jakob, A guide to 17beta-hydroxysteroid dehydrogenases. Mol Cell Endocrinol 171 (2001) 1-4.

[202] R. Mindnich, D. Deluca, and J. Adamski, Identification and characterization of 17 betahydroxysteroid dehydrogenases in the zebrafish, Danio rerio. Mol Cell Endocrinol 215 (2004) 19-30. 
[203] R. Mindnich, M. Hrabe de Angelis, and J. Adamski, Functional genome analysis indicates loss of 17beta-hydroxysteroid dehydrogenase type 2 enzyme in the zebrafish. J Steroid Biochem Mol Biol 103 (2007) 35-43.

[204] R. Mindnich, F. Haller, F. Halbach, G. Moeller, M. Hrabe de Angelis, and J. Adamski, Androgen metabolism via 17beta-hydroxysteroid dehydrogenase type 3 in mammalian and non-mammalian vertebrates: comparison of the human and the zebrafish enzyme. J Mol Endocrinol 35 (2005) 305-16.

[205] R. Mindnich, and J. Adamski, Functional aspects of 17beta-hydroxysteroid dehydrogenase 1 determined by comparison to a closely related retinol dehydrogenase. J Steroid Biochem Mol Biol 104 (2007) 334-9.

[206] R. Mindnich, and J. Adamski, Zebrafish 17beta-hydroxysteroid dehydrogenases: an evolutionary perspective. Mol Cell Endocrinol 301 (2009) 20-6.

[207] J.S. Ings, and G.J. Van Der Kraak, Characterization of the mRNA expression of StAR and steroidogenic enzymes in zebrafish ovarian follicles. Mol Reprod Dev 73 (2006) 943-54.

[208] D.W. Russell, and J.D. Wilson, Steroid 5 alpha-reductase: two genes/two enzymes. Annu Rev Biochem 63 (1994) 25-61.

[209] G.V. Callard, Z. Petro, and K.J. Ryan, Aromatization and 5 alpha-reduction in brain and nonneural tissues of a cyclostome, Petromyzon marinus. Gen Comp Endocrinol 42 (1980) 155-9.

[210] M. Mathieu, A.G. Mensah-Nyagan, M. Vallarino, J.L. Do-Rego, D. Beaujean, D. Vaudry, V. Luu-The, G. Pelletier, and H. Vaudry, Immunohistochemical localization of 3 beta-hydroxysteroid dehydrogenase and 5 alpha-reductase in the brain of the African lungfish Protopterus annectens. J Comp Neurol 438 (2001) 123-35.

[211] G. Hazell, S. Yao, J. Roper, E. Prossnitz, A.M. O'Carroll, and S. Lolait, Localisation of GPR30, a novel $G$ protein-coupled oestrogen receptor, suggests multiple functions in rodent brain and peripheral tissues. J Endocrinol (2009).

[212] E. Brailoiu, S.L. Dun, G.C. Brailoiu, K. Mizuo, L.A. Sklar, T.I. Oprea, E.R. Prossnitz, and N.J. Dun, Distribution and characterization of estrogen receptor G protein-coupled receptor 30 in the rat central nervous system. J Endocrinol 193 (2007) 311-21.

[213] Y. Pang, J. Dong, and P. Thomas, Estrogen signaling characteristics of Atlantic croaker G protein-coupled receptor 30 (GPR30) and evidence it is involved in maintenance of oocyte meiotic arrest. Endocrinology 149 (2008) 3410-26.

[214] Y. Pang, and P. Thomas, Involvement of estradiol-17beta and its membrane receptor, G protein coupled receptor 30 (GPR30) in regulation of oocyte maturation in zebrafish, Danio rario. Gen Comp Endocrinol 161 (2009) 58-61.

[215] P. Thomas, G. Dressing, Y. Pang, H. Berg, C. Tubbs, A. Benninghoff, and K. Doughty, Progestin, estrogen and androgen G-protein coupled receptors in fish gonads. Steroids 71 (2006) 310-6.

[216] X. Liu, P. Zhu, K.W. Sham, J.M. Yuen, C. Xie, Y. Zhang, Y. Liu, S. Li, X. Huang, C.H. Cheng, and H. Lin, Identification of a membrane estrogen receptor in zebrafish with homology to mammalian GPER and its high expression in early germ cells of the testis. Biol Reprod 80 (2009) 1253-61.

[217] I. Skromne, and V.E. Prince, Current perspectives in zebrafish reverse genetics: moving forward. Dev Dyn 237 (2008) 861-82.

[218] M. Kishida, M. McLellan, J.A. Miranda, and G.V. Callard, Estrogen and xenoestrogens upregulate the brain aromatase isoform (P450aromB) and perturb markers of early development in zebrafish (Danio rerio). Comp Biochem Physiol B Biochem Mol Biol 129 (2001) 261-8. 
[219] F. Gubert, C. Zaverucha-do-Valle, P.M. Pimentel-Coelho, R. Mendez-Otero, and M.F. Santiago, Radial glia-like cells persist in the adult rat brain. Brain Res 1258 (2009) 4352. 


\section{Legends to figures}

Figure 1: Changes in brain aromatase activity (AA) in the sea bass over the annual cycle. Changes in AA ( $\mathrm{pmol} / \mathrm{mg}$ prot/h) are illustrated in parallel to changes in the gonadosomatic index (GSI) and sex steroid levels of testosterone (T) or estradiol (E2) (in $\mathrm{ng} / \mathrm{ml}$ plasma). The horizontal black bar indicates the extent of the spawning season for this species that spawns in winter. Data are expressed as mean \pm SEM. Errors that are essentially equal or smaller than the size of data points are not shown. From Gonzalez and Piferrer, 2003 [30].

Figure 2: A phylogenic tree of Cyp19a1 genes of vertebrates showing that the presence of two genes is observed only in teleosts, following the divergence of Actinopterygians from the Sarcopterygians. Note the unique position of the eel cyp19al sequence. The tree was constructed using an online phylogeny program (http://www.phylogeny.fr). The mammalian CYP19 proteins from Homo sapiens (AAA52141) and Mus musculus (BAA00551) served as the outgroup to root the tree. Comparisons were made with the amino acid sequences (GenBank protein ID number respectively from brain and ovary when two genes were identified between brackets) of Dasyatis Sabina/Atlantic stingray (AAF04617), Anguilla japonica/Japanese eel (AAS47028), Carassius auratus/Goldfish (BAA23757; BAA23758), Cromileptes altivelis/Humpback grouper (AAV91181; AAV91178), Cynoglossus semilaevis/Tongue sole (ABM90641; ABL74474), Cyprinus carpio/Common carp (ACB13198; ACB13197), Danio rerio/Zebrafish (AAV41033; AAK00643), Dicentrarchus labrax/Sea bass (AAM95455; CAC21712), Epinephelus akaara/Hong Kong grouper (AAS58447; AAS58448), Epinephelus coioides/Orange-spotted grouper (AAR97602; AAR97601), Fundulus heteroclitus/Mummichog (AAR97269; AAR97268), Gobiodon histrio/Green clown goby (AAV91180; AAV91177), Halichoeres 
tenuispinis/Chinese Wrasse (AAR37047; AAR37048), Hippoglossus hippoglossus/Atlantic halibut (AAY26901; CAC36394), Ictalurus punctatus/Channel catfish (AAL14612; AAB32613), Kryptolebias marmoratus/Mangrove rivulus (ABC68613; ABC68614), Mugil cephalus/Black mullet (AAW72730; AAW72732), Odontesthes bonariensis/Argentinian silverside (AAQ88434; ABK30807), Oreochromis mossambicus/Java tilapia (AAD31030; AAD31031), Oryzias latipes/Japanese medaka (AAP83449; BAA11656), Pseudolabrus japonicas/Wrasse (ABB96486; ABB96485), Rhabdosargus sarba/Goldlined seabream (ABC70868; ABC70869), Silurus meridionalis/Catfish (AAP83132; AAP83133), Takifugu rubripes/Fugu rubripes (BAF93507; BAF93506).

Figure 3: Comparative syntenies around aromatase genes. The cyp19ala and cyp19alb genes are located on LG18 and LG25, respectively. The syntenies are shown and loci are listed in the order in which they appear on the human chromosome. The results indicate that these two linkage groups have a number of loci also observed on human chromosome 15 . These results suggest that zebrafish linkage groups 18 and 25 are duplicates of a portion of human chromosome 15q. A hypothesis for the evolution of chromosomes, aromatase genes, and expression domains is presented below the synteny maps. From Chiang et al., 2001 [43]

Figure 4: Radio-autographic film showing the hybridization signal obtained with the cyp19a1b riboprobe on a series of representative sections of the brain of mature female rainbow trout. It is important to remember that the telencephalon of fish has a single median telencephalic ventricle due to its development by eversion. All micrographs correspond to the same experiment; for better visualization, the films have been inverted. A-H: Transverse sections hybridized with the antisense riboprobe. I: sagittal section hybridized with the antisense (I). Scale bar $=2.5 \mathrm{~mm}$. Abbreviations : bo bulbus olfactorius; $\mathrm{C}$ corpus of the cerebellum; cho chiasma opticum; D area dorsalis telencephali; Dd area dorsalis telencephali pars dorsalis ; Dl area dorsalis telencephali pars lateralis ; Dm area dorsalis 
telencephali pars medialis; inf infundibulum; mo medulla oblongata; nlt nucleus lateralis tuberis ; pi pars intermedia of the pituitary ; Pit pituitary ; Ppa regio preoptica parvocellularis pars anterior ; ppd proximal pars distalis of the pituitary ; Ppa regio preoptica parvocellularis pars posterior ; PVO paraventricular organ ; rl recessus lateralis ; rp recessus posterior ; sc nucleus suprachiasmaticus ; stgl stratum glomerulosum of the olfactory bulb ; stgr stratum granulare of the olfactory bulb; sv saccus vasculosus; tect optic tectum; Thv thalamus ventralis, tl torus longitudinalis; ts torus semicircularis; valv valvula cerebelli ; Vd area ventralis telencephali pars dorsalis ; Ve4 fourth ventricle ; Vv area ventralis telencephali pars ventralis. From Menuet et al., 2003 [60].

Figure 5: Comparative distribution of aromatase B protein, cyp19alb mRNAs and cyp19albGFP in the brain of adult zebrafish

A to $\mathbf{H}$ : Distribution of aromatase BAroB-positive structures on representative transverse sections of the brain of zebrafish. From Menuet et al. 2005 [62].

A' to H': Transversal brain sections of cyp19alb-GFP transgenic fish line [66] showing the expression of GFP in radial glial cells (cell bodies and processes) in different brain nuclei. Note that GFP expression recapitulates that of aromatase B (A to $\mathrm{H}$ ).

A" to H': Arematase BFluorescence in situ hybridization_-on paraffin brain sections showing cyp19alb transcripts (red) the expression of AroB transeripts, in periventricular layers but also in processes crossing the parenchyma until the periphery. Note the accumulation of messengers at the periphery of the brain (B', C', E', F', G'). The blue colour corresponds to DAPI staining.

Abbreviations: A, anterior thalamic nucleus; APN, accessory pretectal nucleus; ATN, anterior tuberal nucleus; CCe, corpus cerebelli; Chab, habenular commissure; Chor, horizontal commissure; $\mathrm{CM}$, corpus mamillare; $\mathrm{CP}$, central posterior thalamic nucleus; $\mathrm{CPN}$, central pretectal nucleus; Cpop, postoptic commissure; Cpost, posterior commissure; D, dorsal 
telencephalic area; Dc, central zone of dorsal telencephalic area; D1, lateral zone of dorsal telencephalic area; Dm, medial zone of dorsal telencephalic area; DOT, dorsomedial optic tract; Dp, posterior zone of dorsal telencephalic area; DP, dorsal posterior thalamic nucleus; ECL, external cellular layer of olfactory bulb; EG, eminentia granularis; ENv, entopenduncular nucleus, ventral part; FR, fasciculus retroflexus; GL, glomerular layer of olfactory bulb; Had, dorsal habenular nucleus; Hav, ventral habenular nucleus; Hc, caudal zone of periventricular hypothalamus; Hv, ventral zone of periventricular hypothalamus; ICL, internal cellular layer of olfactory bulb; IL, inferior lobe; LH, lateral hypothalamic nucleus; LR, lateral recess of diencephalic nucleus; MLF, medial longitudinal fascicle; NMLF, nucleus of medial longitudinal fascicle; PG, preglomerular nucleus; PGa, anterior preglomerular nucleus; PGl, lateral preglomerular nucleus; Pit, pituitary; PP, periventricular pretectal nucleus; PO, posterior pretectal nucleus; PPa, parvocellular preoptic nucleus, anterior part; PPp, parvocellular preoptic nucleus, posterior part; PR, posterior recess of diencephalic ventricle; PSp, parvocellular superficial pretectal nucleus; PTN, posterior tuberal nucleus; R, rostrolateral nucleus; RF, reticular formation; SC, suprachiasmatic nucleus; SD, saccus dorsalis; SO, secondary octaval population; TeO, tectum opticum; TL, torus longitudinalis; TLa, torus lateralis; TPp, periventricular nucleus of posterior tuberculum; TS, torus semicircularis; V, ventral telencephalic area; V3, third ventricle; VII, sensory root of the facial nerve; VIII, octaval nerve; VCe, valvula cerebelli; Vd, dorsal nucleus of ventral telencephalic area; VL, ventrolateral thalamic nucleus; VM, ventromedial thalamic nucleus; VOT, ventrolateral optic tract; $\mathrm{Vp}$, postcommissural nucleus of ventral telencephalic area; Vv, ventral nucleus of ventral telencephalic area; ZL, zona limitans.

Bar $=200 \mu \mathrm{m}\left(\right.$ A to H); $100 \mu \mathrm{m}\left(\mathrm{A}^{\prime}, \mathrm{C}^{\prime}, \mathrm{A}^{\prime \prime}, \mathrm{B}\right.$ ', C', F', G' $) ; 50 \mu \mathrm{m}\left(\mathrm{D}^{\prime}, \mathrm{E}^{\prime}, \mathrm{F}^{\prime}, \mathrm{D}^{\prime \prime}, \mathrm{E}^{\prime \prime}\right)$; $25 \mu \mathrm{m}\left(\mathrm{B}^{\prime}, \mathrm{G}^{\prime}, \mathrm{H}^{\prime}, \mathrm{H}^{\prime}\right.$ ') 
Figure 6: Cyp19a1b-GFP (AroB-GFP) radial glial cells co-express BLBP in the adult zebrafish brain. The cyp19alb-GFP transgene (green) is co-expressed with the radial glial marker BLBP (red) in most brain regions as shown by the yellow colour obtained after merging. Vv, ventral nucleus of dorsal telencephalic area; Hv, ventral zone of periventricular hypothalamus; PR, posterior recess of diencephalic ventricle $\operatorname{Bar}=50 \mu \mathrm{m}(\mathrm{Hv}) ; 25 \mu \mathrm{m}(\mathrm{Vv}$ and PR $)$

Figure 7: Organization of the cyp19a1b promoter in different teleost species: The 200bp around the estrogen responsive element in six fish promoters were analyzed with the MatInspector program (http://www.genomatix.de). Putative responsive elements (matrix similarity > 0.9) for transcription factors known for being expressed in neurons were positioned on each promoter. The structures of each mRNA (Open Reading Frame length and exons organization) are indicated on the right side.

Figure 8: The capacity of the zebrafish cyp19a1b promoter to respond to estradiol in the presence of an estrogen receptor depends on the cell context. From Menuet et al., 2005 [62]. Cell lines include HeLa, CHO-K1, undifferentiated PC12 (PC12U), NGF-differentiated PC12 (PC12D), undifferentiated P19 (P19U), retinoic acid-differentiated P19 (P19D), and U251-MG (U251). A: Cells were transfected with the cyp19alb-luciferase reporter gene and co-transfected with a control (ctrl) or a zebrafish ER $\alpha$ expression vector $(E R \alpha)$. Cells were treated with $0.1 \%$ ethanol containing (black bars) or not (white bars) 10-8 M E2. B: The same experiment performed with an artificial ERE-tk-Luc reporter shows similar responses in all cell lines with lower E2 induction. Data are expressed as fold induction relative to control vector.

\section{Figure 9:}

A: Partial sequence of the proximal promoter of the zebrafish cyp19alb gene showing the position of the ERE and that of an upstream sequence referred to as GxRE. 
Underlined residues are those mutated in (B). From Le Page et al., 2008 [92]

B: Proteins present in glial cells bind the GxRE using an AGGTCA core sequence. Gel shift assays were performed with whole cell extracts $(5 \mathrm{mg})$ from glial or non-glial cell lines and ${ }^{32} \mathrm{P}$-labeled oligonucleotides (1 ng) containing sequences of wild-type GxRE (P1) or two different mutants (P2, P3) as probes. Whole cell extracts from HELA, PC12, differentiated PC12 (d.PC12) and P19 cells represent non-glial cell contexts, whereas extracts from differentiated P19 (d.P19) and U251-MG cell represent glial cell contexts. The different sequences used as double-stranded probes are indicated on the bottom of the figure (P1,P2 and P3). The control lanes correspond to the ${ }^{32} \mathrm{P}$-labeled oligonucleotides without extracts. Free probes and specific bands corresponding to protein/DNA complexes 1 and 2 are indicated by an arrow. From Le Page et al., 2008 [92].

Figure 10: Cyp19a1b-GFP (AroB-GFP) radial glial cells are proliferative cells in the adult zebrafish brain

Transverse sections showing that some cyp19alb-GFP (AroB-GFP) radial glial cells (green) exhibit PCNA-positive nucleus (red) in the hypothalamus (Hv), in the ventral nucleus of the ventral telencephalon $(\mathrm{Vv})$ or in the posterior recess $(\mathrm{PR})$, indicating that these AroB-positive cells are proliferative cells. Arrows show some doubly labeled cells (AroB and PCNA). Bar $=$ $25 \mu \mathrm{m}$ (Top and bottom panel); $12 \mu \mathrm{m}$ (Middle panel)

Figure 11: Mechanical injury of the telencephalon increases cell proliferation in the periventricular layer and causes increased aromatase expression: Sexually mature zebrafish (3 to 6 months) were anesthetized with tricaine according to the principles for the use and care of laboratory animals, in compliance with French and European regulations on animal welfare. Guided by landmarks localized on the head of the fish, a mechanical lesion was made by lowering a needle (30G x 1/2"; 0.30 x 13 ) into the telencephalon. Directly after the lesion, fish were placed in aquaria $\left(28^{\circ} \mathrm{C}\right)$ and kept for 8 days before sacrifice and brain 
sampling. Aromatase immunohistochemistry was performed as previously described [64]. For PCNA immunohistochemistry, antigen retrieval was done by submersing tissue sections in sodium citrate buffer $\left(\mathrm{pH} 7 ; 64^{\circ} \mathrm{C}\right.$ ) for $90 \mathrm{~min}$. Anti-PCNA (Dako, Clone PC10) was used at $1: 100$.

A and B: PCNA immunohistochemistry (red) showing a strong increase in the number of proliferative cells in the lesioned telencephalic hemisphere (B, ispilateral) compared to the control hemisphere (A, contralateral same section as in $\mathrm{B})$.

C and D: Aromatase B immunohistochemistry (green) in the ispilateral hemisphere (D) and the contralateral hemisphere (C), showing increased aromatase expression following the lesion.

E: Statistical analysis of PCNA cell number in contralateral and ipsilateral telencephalic hemispheres, 8 days after mechanical injury of telencephalon. Statistical analysis is carried by ANOVA on a total of 36 sections from 3 lesioned fish. On the lesioned hemisphere, 2029 PCNA-positive cells were counted on the ipsilateral side compared to 579 on the contralateral one $(* * * \mathrm{P}<0.0001)$.

$\operatorname{Bar}=50 \mu \mathrm{m}$

Figure 12: Hypothesis regarding the potential differences in estrogen production in relation to radial glial cells and the neurogenic activity in teleost fish and rodents: In the rodent, the embryonic neurogenesis is characterized by an intense proliferation that is correlated to a high aromatase activity [13]. Radial glia-like cells, possibly expressing aromatase, at least in the cortex [76], give birth to neurons. After birth, this neurogenic activity decreases rapidly as radial progenitors transform into astrocytes [158]. In the adult brain, this neurogenic activity is confined to two small regions, the dentate gyrus of the hippocampus and the subependymal zone of the lateral ventricles. Aromatase activity is documented in the hippocampus [192], whereas radial glial cells may persist in the 
subependymal zone of the lateral ventricles [219]. In contrast, in teleost fish, the whole brain keeps growing, even in sexually mature fish, and thus conserves throughout life features of the developing brain in rodents (intense neurogenesis, high aromatase activities and persistence of radial progenitors in the entire brain, except in the cerebellum). 
Click here to download high resolution image

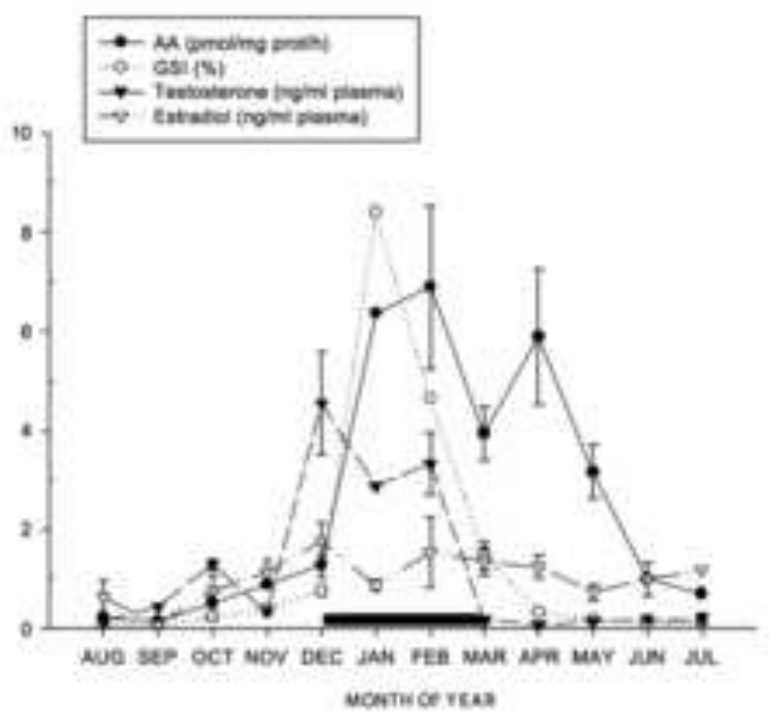

Figure 1 


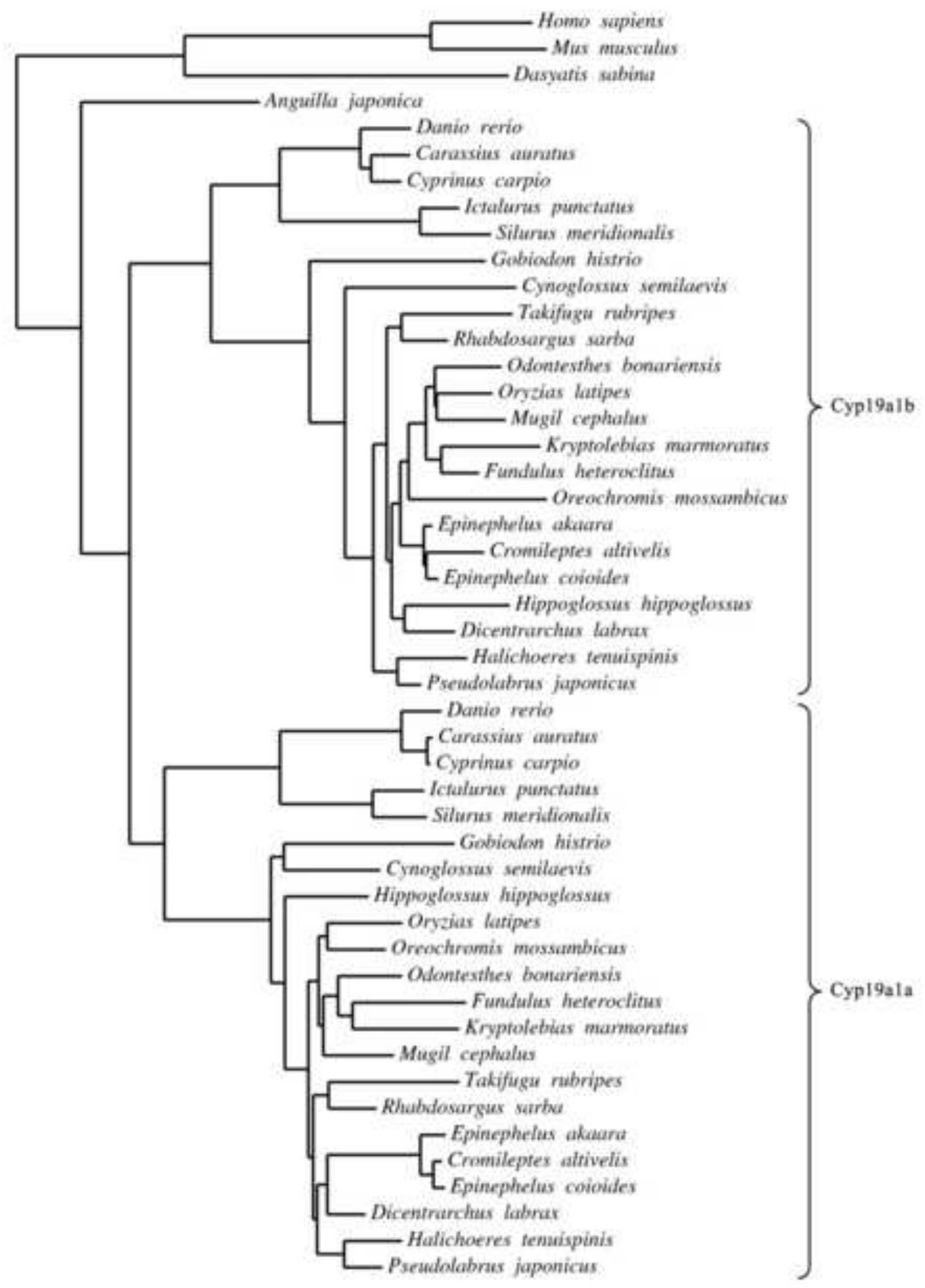

Figure 2 
Click here to download high resolution image

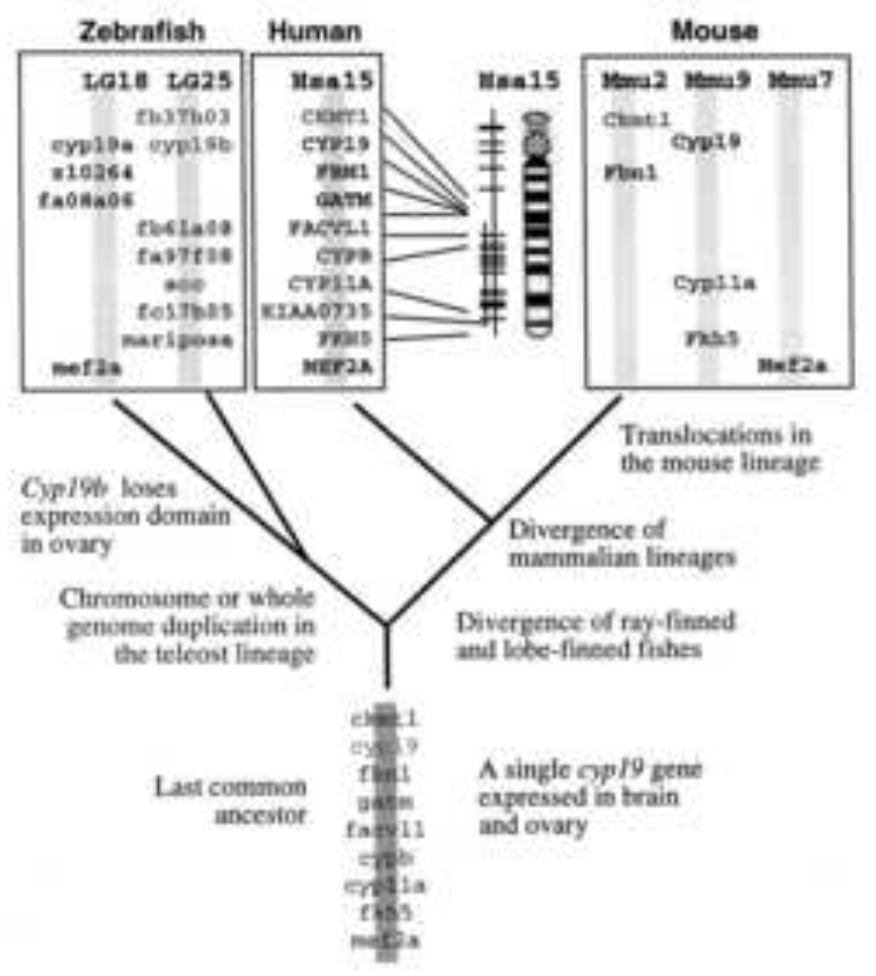

Figure 3 
Figure 4

Click here to download high resolution image
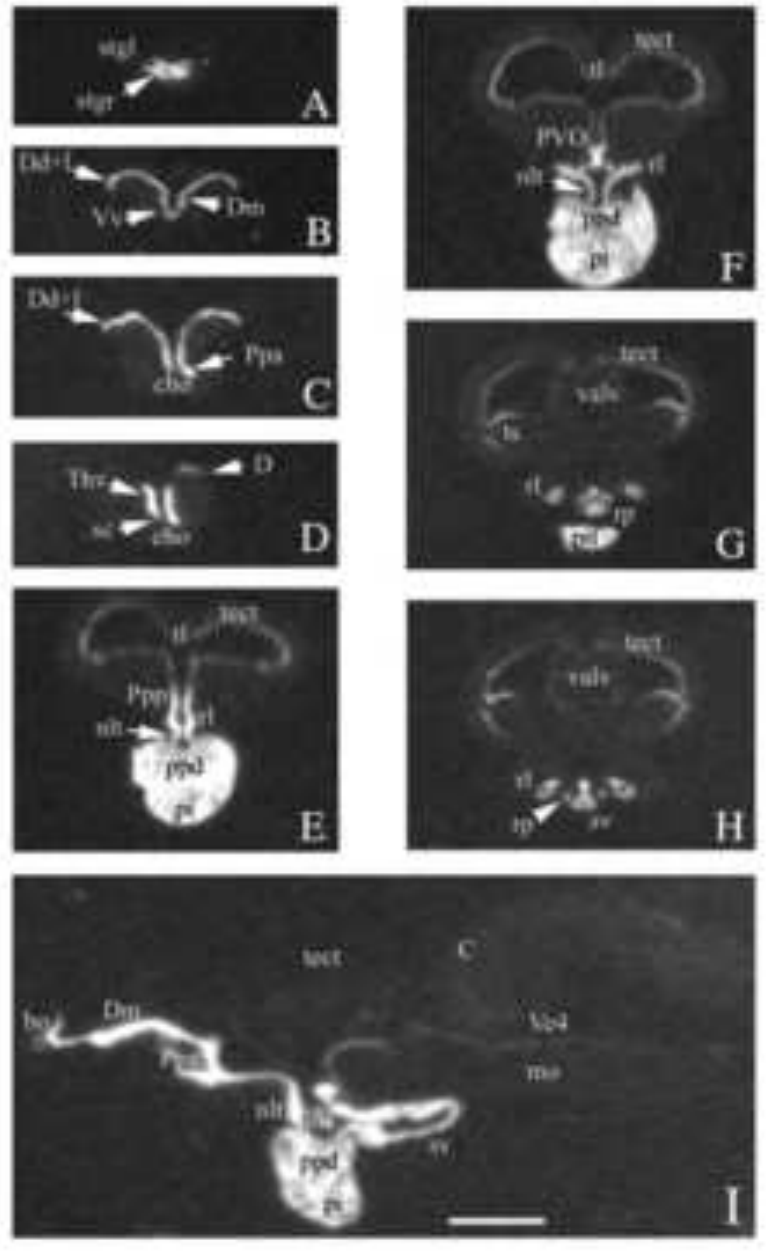

A

\section{Figure 4}

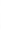

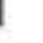

政


Click here to download high resolution image

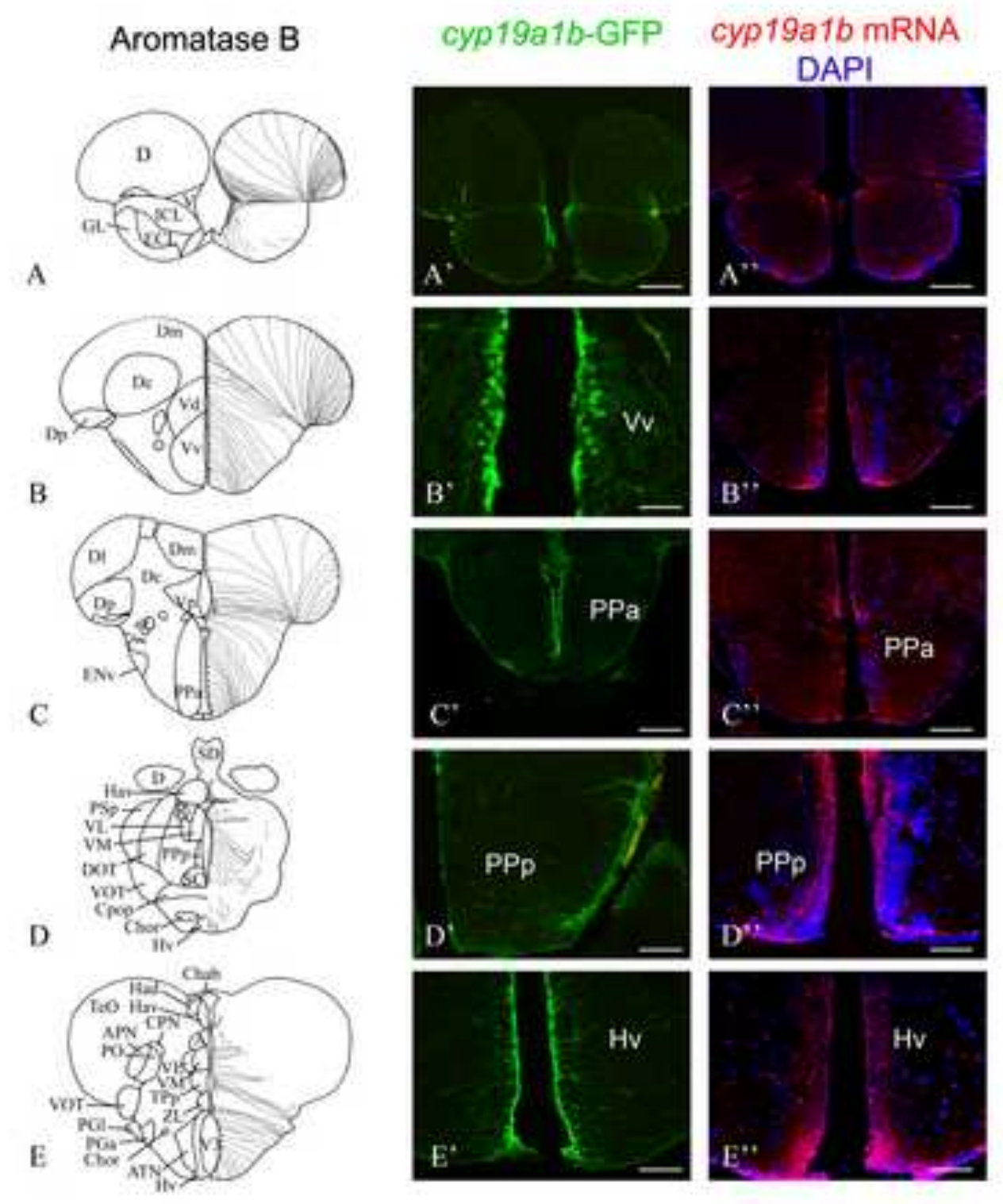

Figure 5 
Figure 5 continued

Click here to download high resolution image
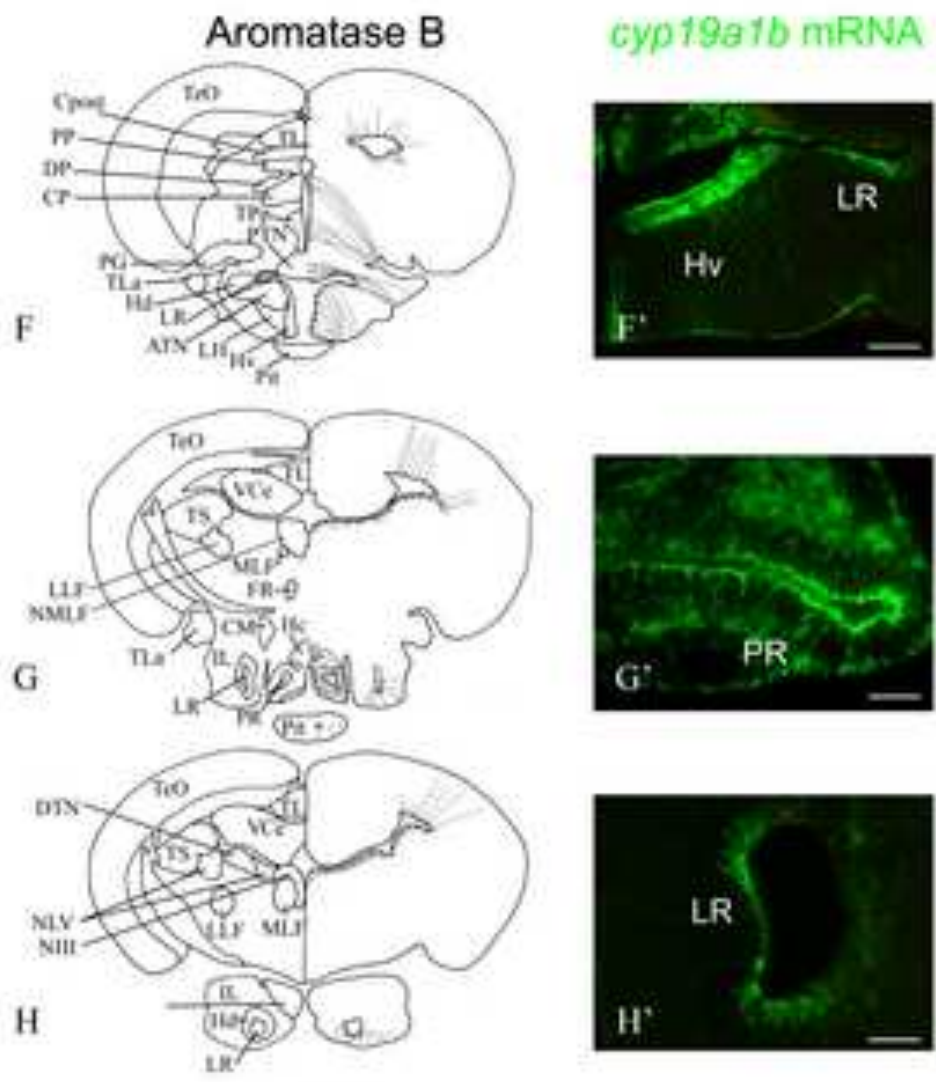

cyp19a1b mRNA

DAPI
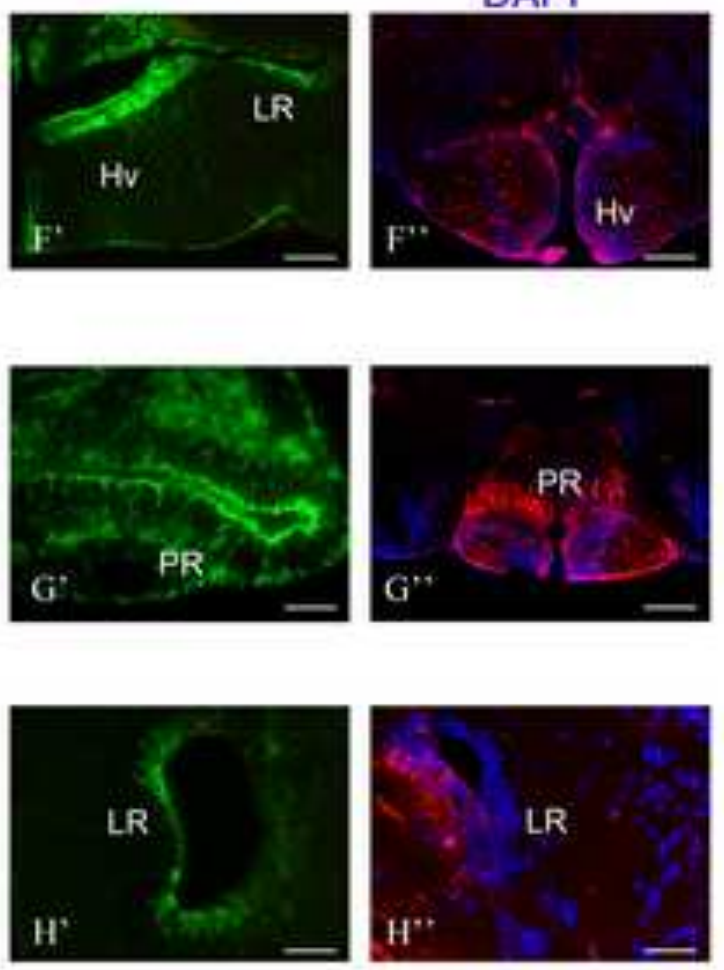

Figure 5 continued 
Click here to download high resolution image
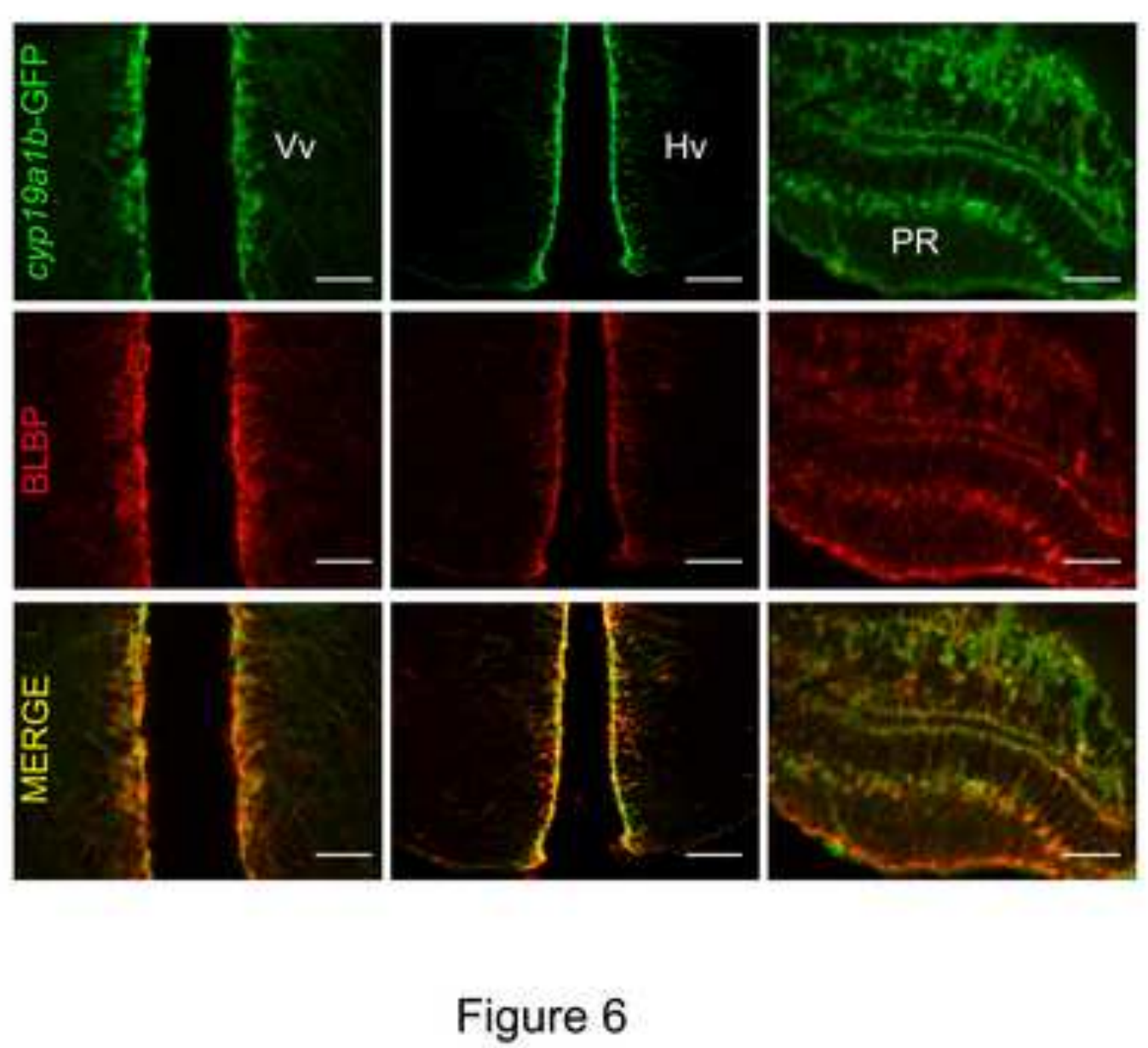

Figure 6

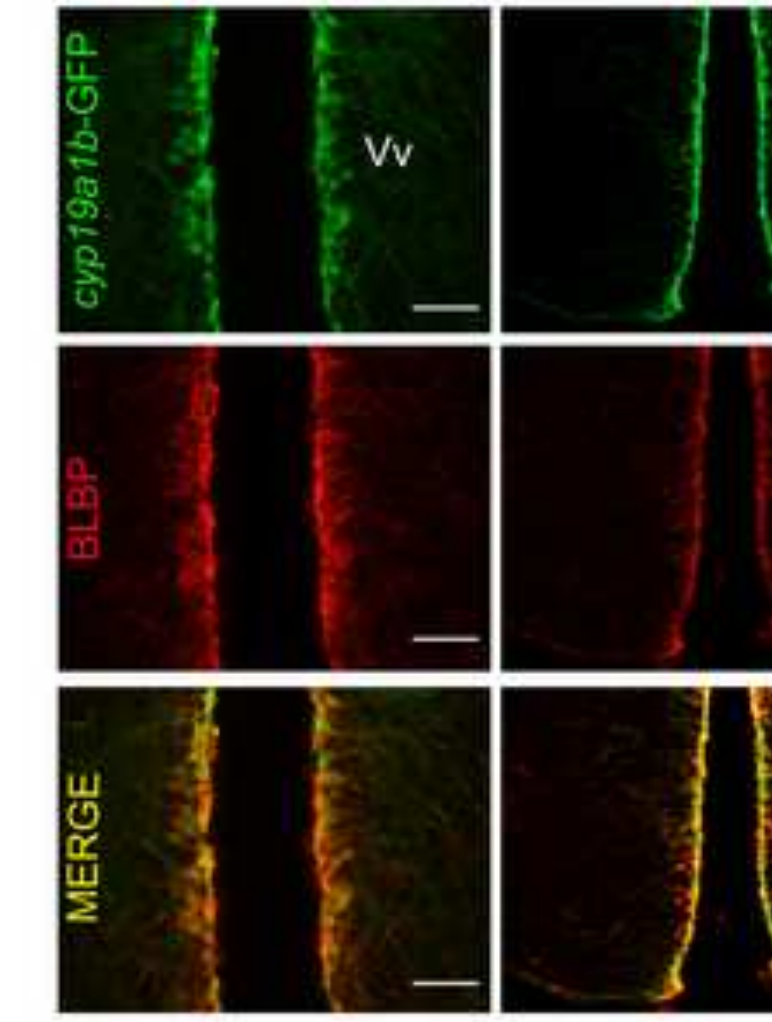

,

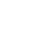

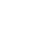

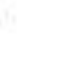

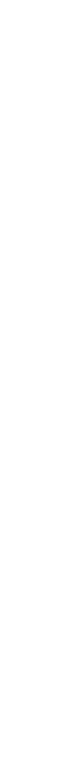

$\mathrm{H}$
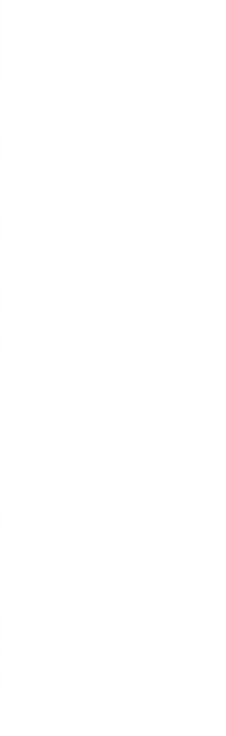

\author{
Figure 6
}
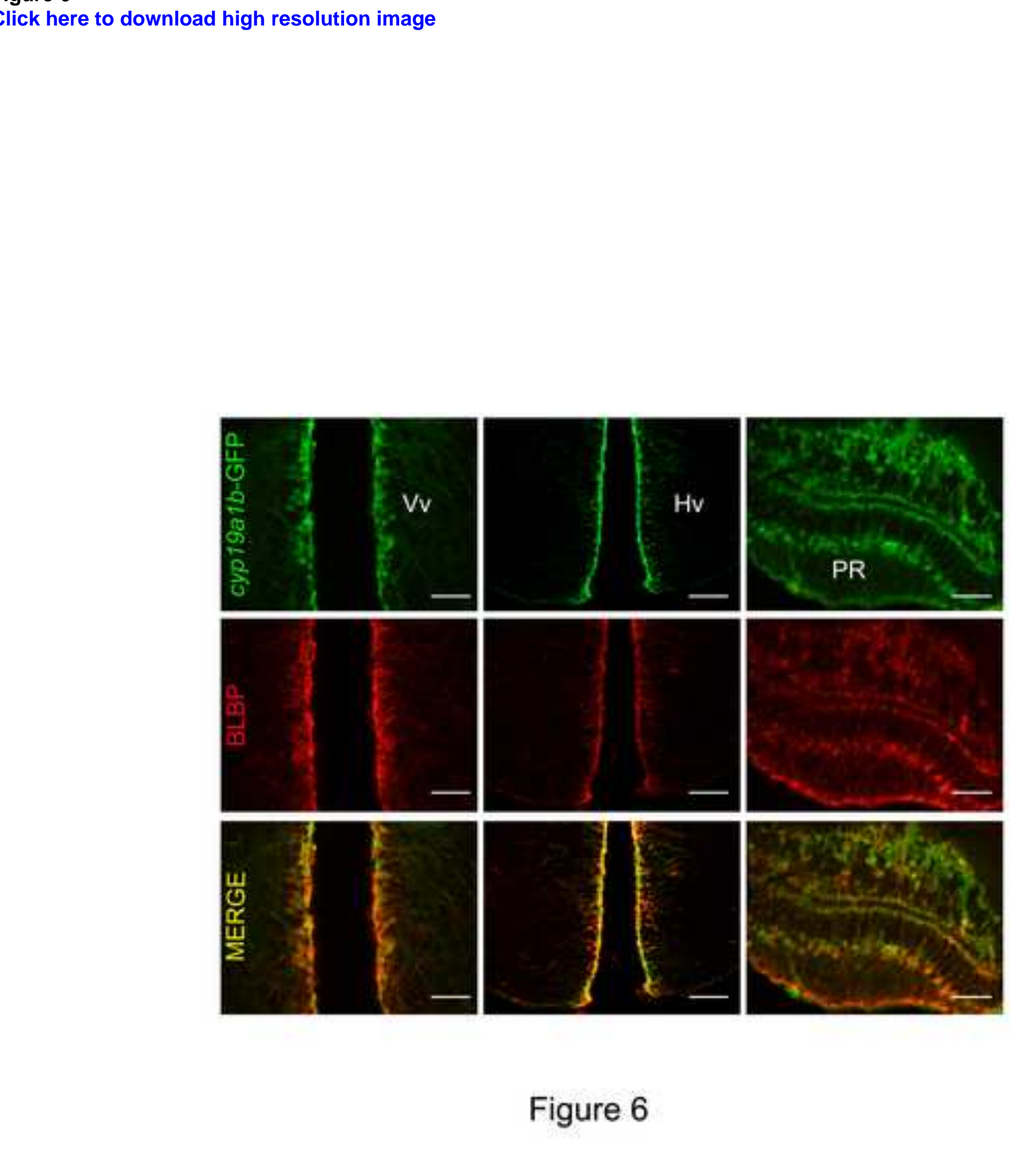
Figure 7
Click here to download high resolution image

Figure 7
Click here to download high resolution image

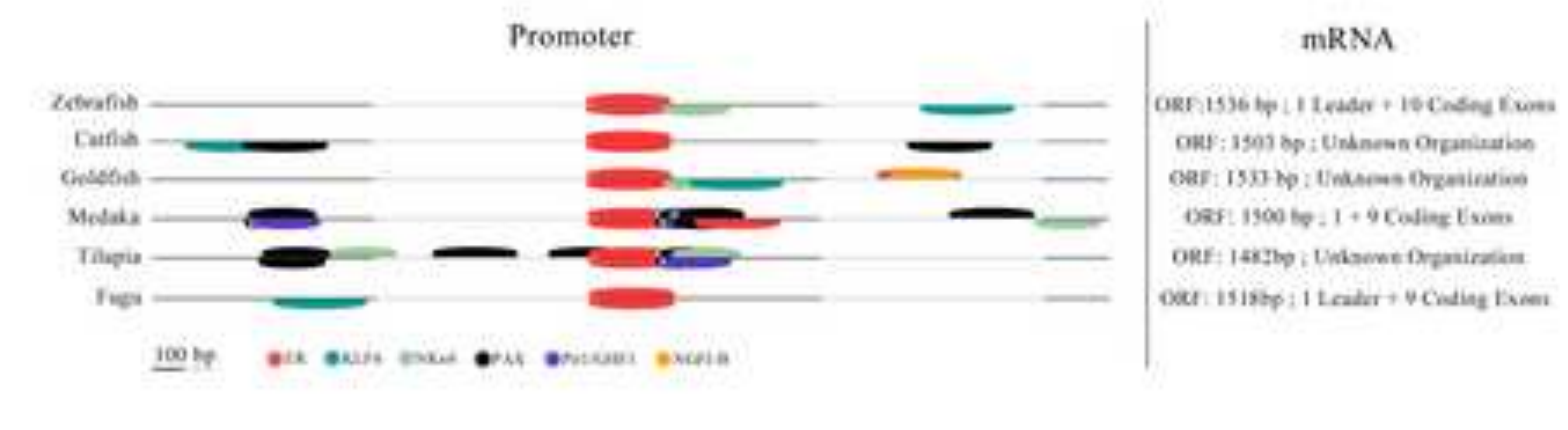

Figure 7

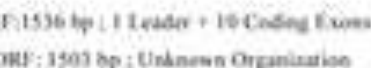

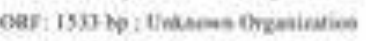

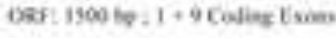

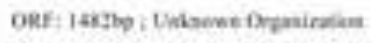

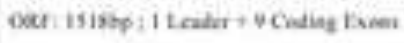

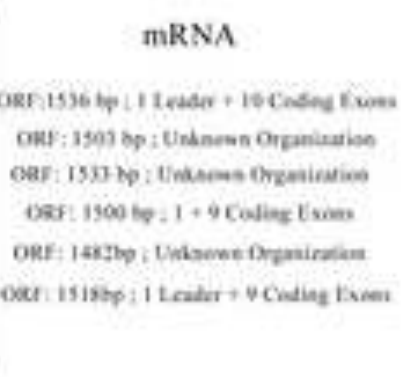

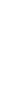


Click here to download high resolution image

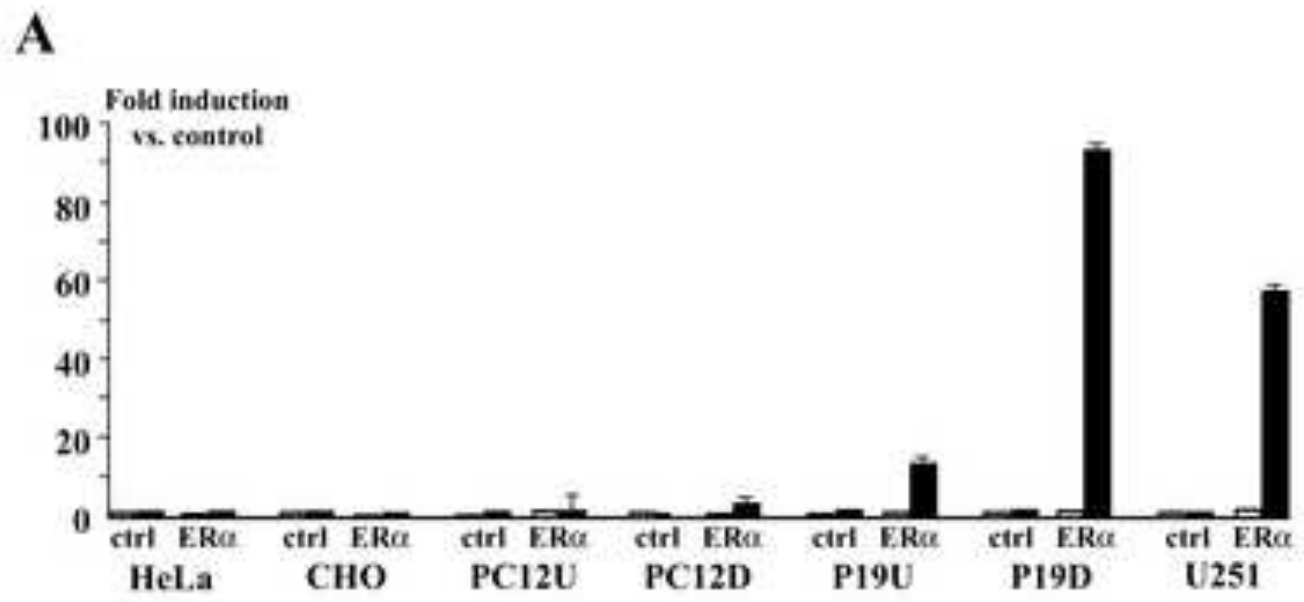

B

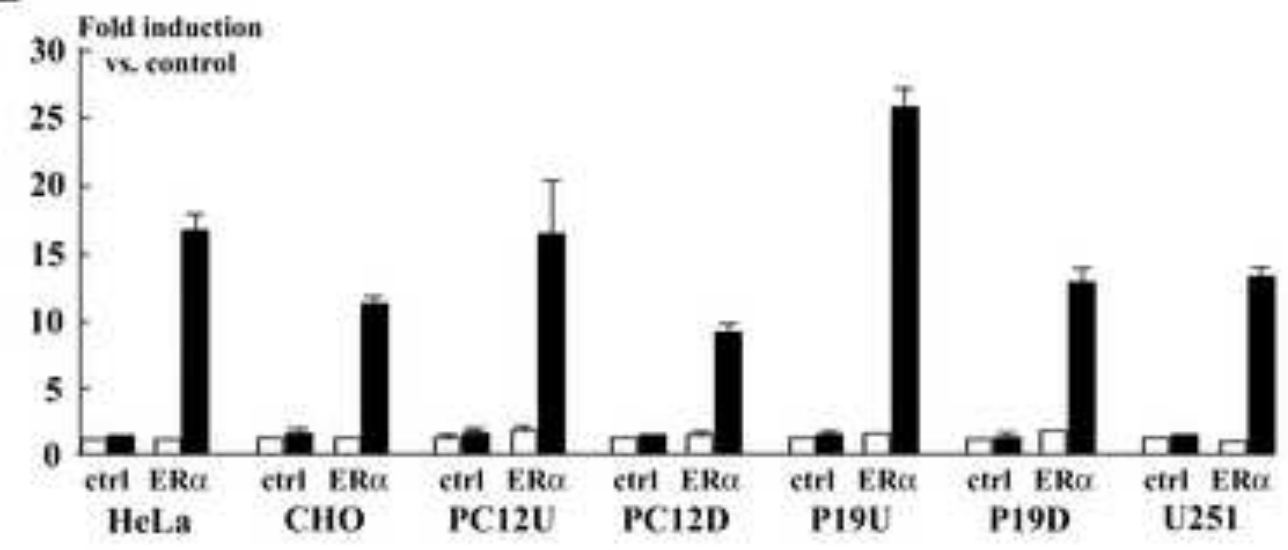

Figure 8 
A

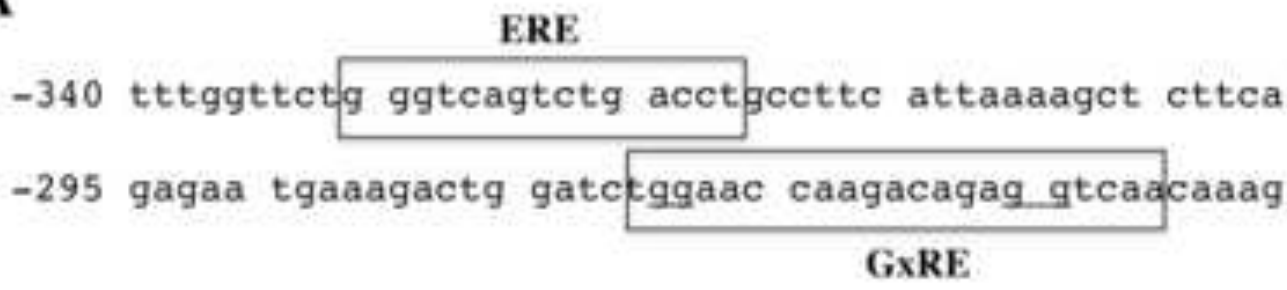

B
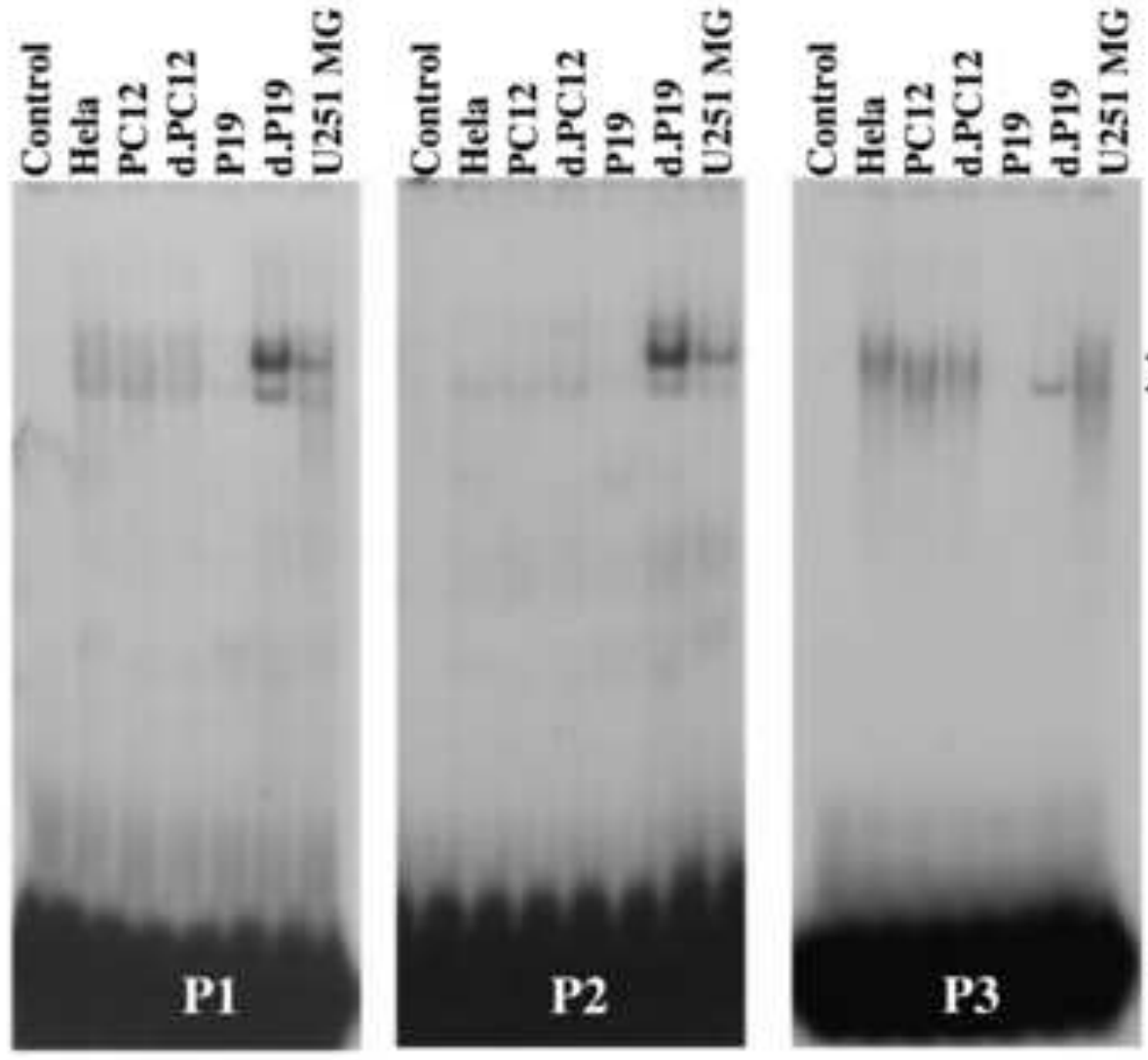

Complex 1

4 Complex 2

Sequences of the probes used for the gel shifts

P1: GACTGGATCTGGAACCAAGACAGAGGTCAACA

P2: GACTGGATCTaAAACCAAGACAGAGGTCAACA

P3: GACTGGATCTGGAACCAAGACAGAaaTCAACA

Figure 9 
Click here to download high resolution image
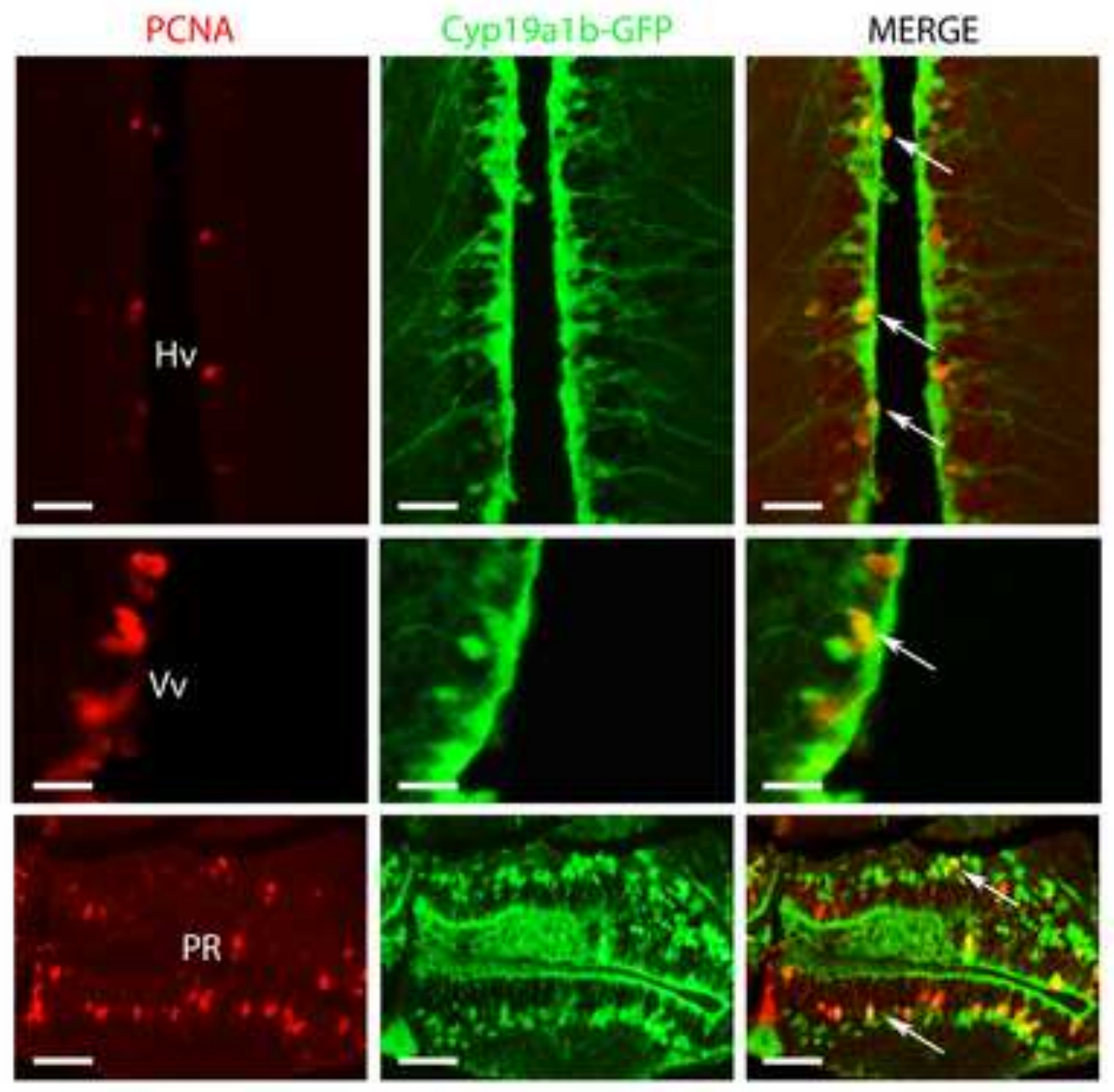

Figure 11 


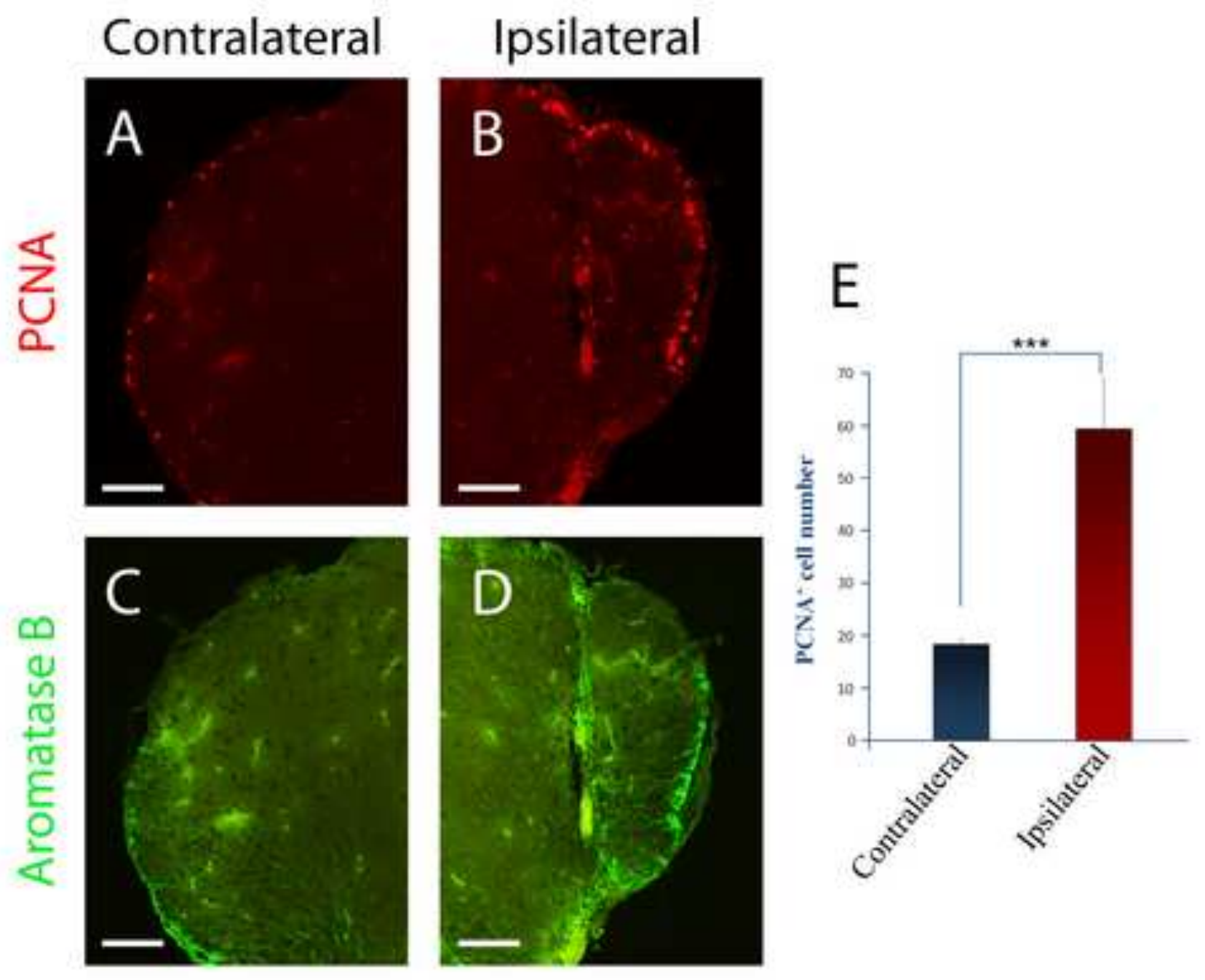

Figure 12 


\section{Figure 12}

Click here to download high resolution image

\section{RODENT}

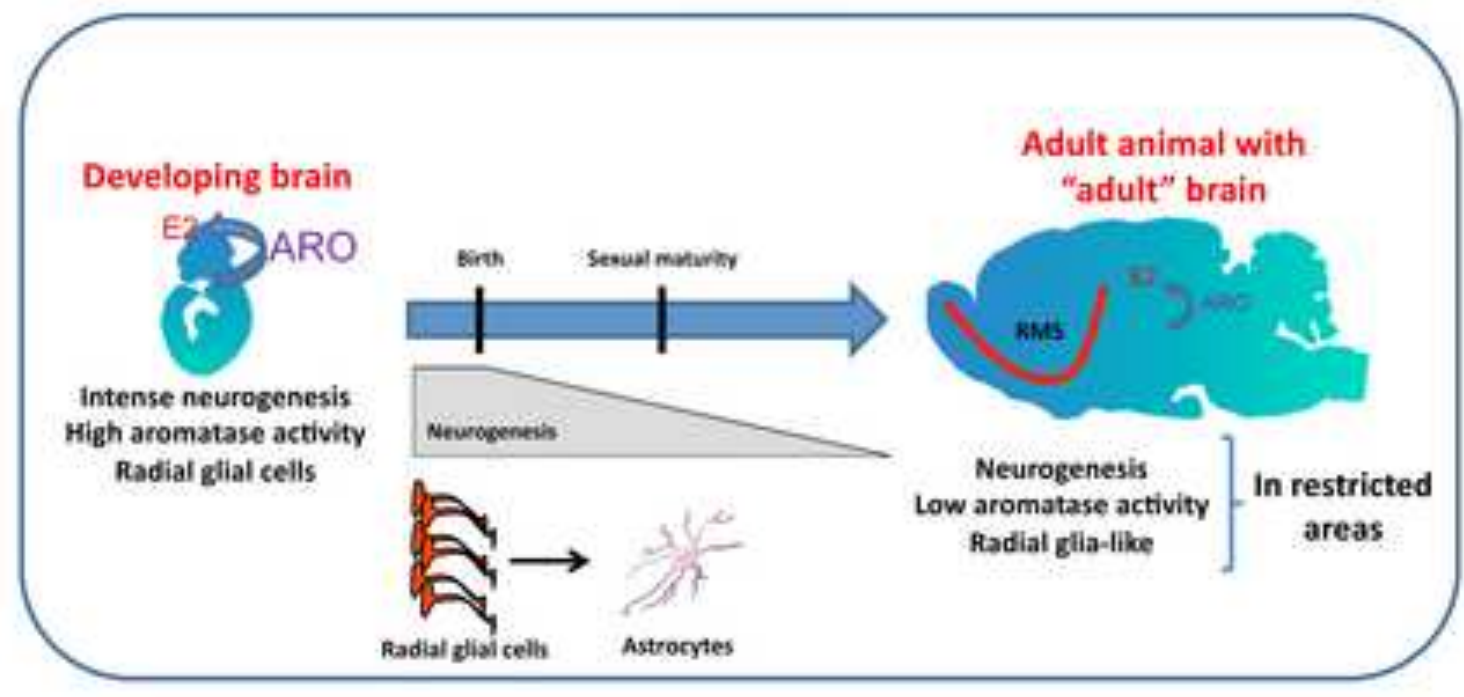

TELEOST FISH

Developing brain

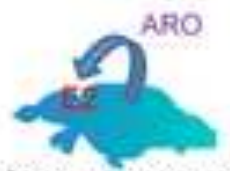

Intense neurogenesis Moderate aromatase activity

Radial glial cells

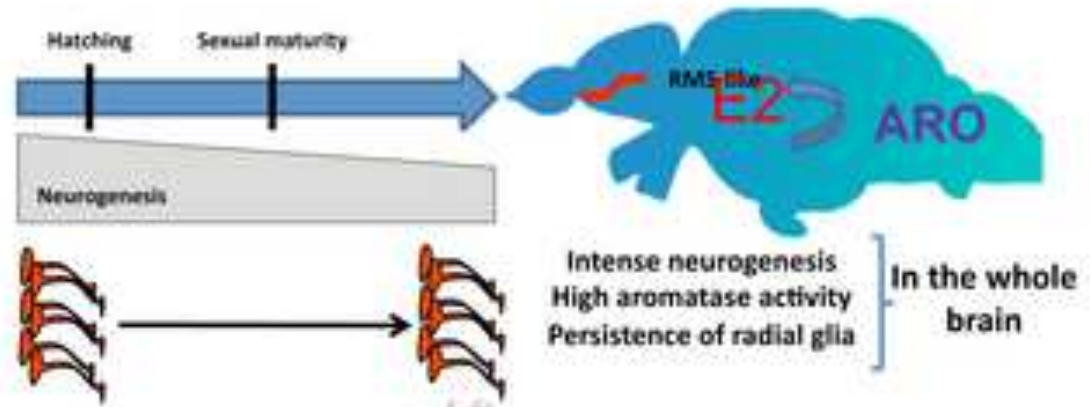

Sexually adult animal with "developing" brain In the whole Persistence of redial glia 